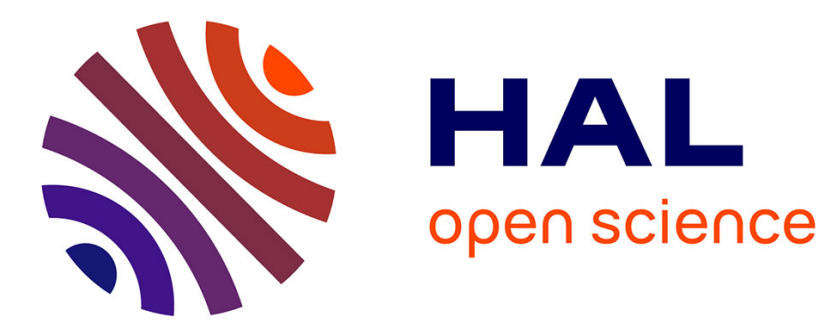

\title{
International trade and technological competition in markets with dynamic increasing returns
}

\author{
Luca Fontanelli, Mattia Guerini, Mauro Napoletano
}

\section{To cite this version:}

Luca Fontanelli, Mattia Guerini, Mauro Napoletano. International trade and technological competition in markets with dynamic increasing returns. 2021. hal-03370650

\section{HAL Id: hal-03370650 \\ https://hal-sciencespo.archives-ouvertes.fr/hal-03370650}

Preprint submitted on 8 Oct 2021

HAL is a multi-disciplinary open access archive for the deposit and dissemination of scientific research documents, whether they are published or not. The documents may come from teaching and research institutions in France or abroad, or from public or private research centers.
L'archive ouverte pluridisciplinaire HAL, est destinée au dépôt et à la diffusion de documents scientifiques de niveau recherche, publiés ou non, émanant des établissements d'enseignement et de recherche français ou étrangers, des laboratoires publics ou privés. 


\section{SciencesPo}

INTERNATIONAL TRADE AND TECHNOLOGICAL COMPETITION IN MARKETS WITH DYNAMIC INCREASING RETURNS

Luca Fontanelli

Mattia Guerini

Mauro Napoletano

SCIENCES PO OFCE WORKING PAPER $n^{\circ} 21 / 2021$ 


\title{
ofce
}

\section{SciencesPo}

\author{
EDITORIAL BOARD
}

Chair: Xavier Ragot (Sciences Po, OFCE)

Members: Jérôme Creel (Sciences Po, OFCE), Eric Heyer (Sciences Po, OFCE), Sarah Guillou (Sciences Po, OFCE), Xavier Timbeau (Sciences Po, OFCE)

\section{CONTACT US}

OFCE

10 place de Catalogne | 75014 Paris | France

Tél. +33144185424

www.ofce.fr

This Working Paper:

Luca Fontanelli, Mattia Guerini and Mauro Napoletano

International Trade and Technological Competition in Markets with Dynamic Increasing Returns Sciences Po OFCE Working Paper, $\mathrm{n}^{\circ} 21 / 2021$.

Downloaded from URL: www.ofce.sciences-po.fr/pdf/dtravail/WP2021-21.pdf

DOI - ISSN 
ABOUT THE AUTHORS

Luca Fontanelli, Université Côte d'Azur, CNRS, GREDEG, Institute of Economics, Scuola Superiore Sant'Anna, Italy Email Address: luca.fontanelli@univ-cotedazur.fr

Mattia Guerini, University of Brescia, Université Côte d'Azur, CNRS, GREDEG, Institute of Economics, Scuola Superiore Sant'Anna, Italy

Email Address: mattia.querini@unibs.it

Mauro Napoletano, Université Côte d'Azur, CNRS, GREDEG, Sciences Po-OFCE, SKEMA Business School, Institute of Economics, Scuola Superiore Sant'Anna, Italy

Email Address: mauro.napoletano@univ-cotedazur.fr

\section{ABSTRACT}

We build a simple dynamic model to study the effects of technological learning, market selection and international competition in the determination of export flows and market shares. The model features two countries populated by firms with heterogeneous productivity levels and sales. Market selection in each country is driven by a finite pairwise Pólya urn process. We show that market selection leads either to a national or to an international monopoly in presence of a static distribution of firm productivity levels. We then incorporate firm learning and entry-exit in the model and we show that the market structure does not converge to a monopoly. In addition, we show that the extended model is able to jointly reproduce a wide ensemble of stylized facts concerning intra-industry trade, industry and firm dynamics.

KEYWORDS

International trade, industrial dynamics, firm dynamics, market selection, Pólya urn.

J EL

C15, F1, L1. 



\title{
International Trade and Technological Competition in Markets with Dynamic Increasing Returns
}

\author{
Luca Fontanelli $^{\mathrm{a}, \mathrm{b}} \quad$ Mattia Guerini ${ }^{\mathrm{c}, \mathrm{a}, \mathrm{b}} \quad$ Mauro Napoletano ${ }^{\mathrm{a}, \mathrm{d}, \mathrm{e}, \mathrm{b}}$ \\ a Université Côte d'Azur, CNRS, GREDEG, France \\ ${ }^{\mathrm{b}}$ Institute of Economics, Scuola Superiore Sant'Anna, Italy \\ ${ }^{\mathrm{c}}$ University of Brescia \\ ${ }^{\mathrm{d}}$ Sciences Po, OFCE, France \\ e SKEMA Business School, France
}

August 22, 2021

\begin{abstract}
We build a simple dynamic model to study the effects of technological learning, market selection and international competition in the determination of export flows and market shares. The model features two countries populated by firms with heterogeneous productivity levels and sales. Market selection in each country is driven by a finite pairwise Pólya urn process. We show that market selection leads either to a national or to an international monopoly in presence of a static distribution of firm productivity levels. We then incorporate firm learning and entry-exit in the model and we show that the market structure does not converge to a monopoly. In addition, we show that the extended model is able to jointly reproduce a wide ensemble of stylized facts concerning intra-industry trade, industry and firm dynamics.
\end{abstract}

Keywords: International trade, industrial dynamics, firm dynamics, market selection, Pólya urn. JEL Codes: C15, F1, L1.

$\bowtie$ Luca Fontanelli - luca.fontanelli@univ-cotedazur.fr.

$凶$ Mattia Guerini - mattia.guerini@unibs.it

$\bowtie$ Mauro Napoletano - mauro.napoletano@univ-cotedazur.fr 


\section{Introduction}

This paper proposes a simple intra-industry model to study the joint effect of imperfect maket selection and learning in the determination of export flows and industry dynamics. Our work belongs to a recent stream of literature that attempts to explain international trade patterns by means of simple stochastic processes (e.g. the "balls and bins" model proposed in Armenter and Koren, 2014) and it contributes to the large theoretical and empirical literature that has stressed the pivotal role of productivity and market selection in determining firm performance in international markets (see e.g. Bernard and Bradford Jensen, 1999; Melitz, 2003). This literature has also highlighted how export performance is not only influenced by the level of productivity (Bernard and Bradford Jensen, 1999), but also by innovation activities and investments in R\&D (Dosi et al., 2015; Grazzi et al., 2021). Furthermore, several works in the industrial dynamics literature have unveiled the presence of wide and persistent productivity differentials among firms (see e.g. Bartelsman and Dhrymes, 1998; Doms and Bartelsman, 2000; Foster et al., 2001; Bottazzi et al., 2010; Dosi et al., 2015). Interestingly, productivity differentials persist also when discriminating between exporting and non exporting firms, as the productivity distributions of exporters and non-exporters remain both right skewed. In addition, notwithstanding the presence of the so called export efficiency premium (Bernard and Jensen, 1995; Bernard and Bradford Jensen, 1999; Bernard et al., 2007), the two distributions partially overlap (Bernard et al., 2003; Mayer and Ottaviano, 2008; Melitz and Trefler, 2012; Impullitti et al., 2013; Grazzi et al., 2021). The latter result indicates the presence of large groups of high productivity non exporters co-existing with low productivity exporters, and thus the presence of an imperfect sorting mechanism in foreign markets. Finally, the increasing importance of international competition, fostered by the fall of trade barriers in the last decades, has increased the awareness about the significant impact of trade flows on industry and firm dynamics. In that respect, recent studies have found that market concentration (di Giovanni et al., 2011) and volatility (di Giovanni and Levchenko, 2009, 2012; Vannoorenberghe, 2012; Ćede et al., 2018; di Giovanni et al., 2019) are positively affected by trade openness.

We contribute to the above literature by building a model of intra-industry trade wherein market selection is driven by a finite pairwise Pólya urn process. ${ }^{1}$ The first applications of Pólya urns in

\footnotetext{
${ }^{1}$ The above process differs from a standard Pólya process in two respects. First, in our model, pairs of firms are
} 
economics date back to the seminal works by Simon (1955), Ijiri and Simon (1975) and Ijiri and Simon (1977) on firm size distribution. Since then, Pólya urn processes have been employed in several domains of economics, and in particular in the analysis of technical change (Arthur et al., 1987; Arthur, 1989; Dosi et al., 1994, 2019) and industry dynamics (Fu et al., 2005; Bottazzi and Secchi, 2006a; Bottazzi et al., 2007; Riccaboni et al., 2008). ${ }^{2}$ However, to the best of our knowledge, so far there is no application of Pólya urns to the analysis of international trade dynamics. ${ }^{3}$

In the model, pairs of firms are randomly drawn with a probability which is proportional to firm size. The two firms in the selected pair then compete for a market opportunity on the basis of their productivity levels. The market opportunity is reallocated from the least productive firm to the most productive one in the pair. The micro-foundation of firm selection according to the above pairwise sampling rule captures the presence of consumers' imperfect knowledge in the product markets and it is similar to models of imperfect competition with random encounters among costumers (see e.g. Phelps and Winter, 1970; Bils, 1989; Rotemberg and Woodford, 1991; Greenwald and Stiglitz, 2005). Furthermore, the assumption that the probability of competing for a market opportunity is an increasing function of market size captures the essence of dynamic increasing returns in market selection (see Arthur, 1989; Dosi and Kaniovski, 1994; Dosi et al., 2019), and it is a proxy for the fact that bigger firms have better distribution channels and are thus more likely to be known among costumers. Finally, competition over the efficiency domain captures the fact that relatively more productive firms are able to charge a lower price and to attract a higher number of consumers, increasing their market shares (Dosi et al., 1995, 2017).

By using the above framework, we first prove analytically that, with a static distribution of firm productivity levels, market selection generates asymptotically either a national or an international monopoly (depending on the presence of iceberg costs). Next, we extend the model to include firm idiosyncratic learning, which affects firm productivity over time, and entry and exit of firms. By randomly drawn on the basis of their respective size whereas only one firm is drawn in the standard process. Second, in the standard Pólya urn processes market demand tends to infinity, as new balls are added to the urn (see also Schreiber, 2001), whereas market size is finite in our context.

${ }^{2}$ Another mechanism similar to our selection process is the brochure mechanism in the Keynes+Schumpeter $(\mathrm{K}+\mathrm{S})$ macroeconomic models proposed by Dosi et al. (see e.g. 2010, 2013, 2015). There, the consumption good firms change their supplier of intermediate capital goods when they receive a signal (a "brochure") from a capital good firm selling a more productive technology.

${ }^{3}$ The unique exception is contained in the Appendix of the work by Dosi et al. (2015) that however employs a Pólya urn scheme different from ours.

${ }^{4}$ In our model the terms productivity, efficiency and competitiveness have the same meaning. 
means of extensive Monte Carlo simulations, we show that the above extended version of the model is able to jointly reproduce the most important stylised facts related to international trade and industry dynamics. We also use this extended version of the model to carry out comparative dynamics exercises. In particular, we show that trade openness and the strength of the market selection process positively affect firm and industry volatility and different measures of market concentration (domestic and export concentration) by means of a winner-takes-all type of dynamics. Overall, the above results indicate that our intra-industry trade model - despite its simplicity - provides a fairly accurate description of how the interplay between cumulative learning and market selection shape the most interesting stylized facts concerning international trade, industry dynamics and firm dynamics. Moreover, our model also generates further predictions worth to investigate in empirical research.

The remainder of the paper is organized as follows. In section 2 we provide a review of the empirical and theoretical literature in trade and industry dynamics related to our work. In section 3 we describe the basic model and we state some propositions on the asymptotic behaviour of the finite Pólya urn mechanism of market selection in presence of a static distribution of firm productivity levels. Section 4 introduces the extended model and reports the results from Monte Carlo simulations, also by discussing its economic implications. Section 5 concludes. The appendix contains the proofs of the propositions stated in the paper.

\section{Empirical and theoretical backgrounds}

We begin by surveying the contributions to the industrial dynamics and international trade literature related to our paper, with a special focus on the interplay between firm learning and market selection, which constitute the two pillars of our model.

Market selection is an imperfect mechanism determining which firms survive in competitive environments (Foster et al., 2001; Bottazzi et al., 2010; Dosi et al., 2015) and shaping the statistical properties of firm-level productivity and size distributions. In that respect, a good deal of empirical contributions has shown that the productivity distribution of firms displays a positive skewness with a long right tail, and it is well approximated by a Log-normal law (Baily et al., 1992; Bartelsman and Dhrymes, 1998). In addition, productivity differentials between firms tend to be persistent over 
time. These properties of the productivity distribution are robust to different levels of aggregation and to different methods of estimation (Doms and Bartelsman, 2000; Syverson, 2011; Dosi and Grazzi, 2006; Bottazzi et al., 2008). In the context of an open economy, it is worth noticing that the presence of wide productivity differentials remains valid also when discriminating between exporting and non exporting firms. In fact, notwithstanding the presence of the so called export efficiency premium (Bernard and Jensen, 1995; Bernard and Bradford Jensen, 1999; Bernard et al., 2007), the two productivity distributions of exporters and non-exporters are both right-skewed and they partially overlap (Mayer and Ottaviano, 2008; Melitz and Trefler, 2012; Grazzi et al., 2021). Thus, there exist a group of high productivity non exporters and a group of low productivity exporters, and the first stochastically dominates the second. ${ }^{5}$ Productivity influences export performance not only in levels. Firms activities related to learning and technical change (such as investment in R\&D, patenting and embodied technologies) are also positively related to export (Dosi et al., 2015; Grazzi et al., 2021).

Similar properties have been uncovered also for the firm size distribution. ${ }^{6}$ Some studies (e.g. Simon and Bonini, 1958; Axtell, 2001) indicate that the aggregate firm size distribution is well approximated by a Pareto law. Nevertheless, the debate on the precise functional form of the size distribution has been vivid because of technical concerns (Bottazzi et al., 2015) and because the properties of the distribution at the sectoral level are quite different from the aggregate ones (Bottazzi and Secchi, 2003). There is however consensus about the fact that the departure from the log-normal benchmark (and the presence of long right tails) is a systematic feature broadly recorded by all empirical studies. Other two important characteristics related to size are (i) the overlap in the two distributions of exporters and non exporters, a fact denoting the co-existence of small exporters and large non exporters (Grazzi et al., 2021) and (ii) a fatter and longer right tail in the size distribution of exporters with respect to the one of non-exporters (di Giovanni et al., 2011). This last feature can be explained by the distribution of the export sales by exporter firms: the vast majority of total export flows derives indeed from a small number of very large firms (Mayer and Ottaviano, 2008; Eaton et al., 2011; Freund and Pierola, 2015; Gaubert and Itskhoki, 2018). Finally, the process of market se-

\footnotetext{
${ }^{5}$ This has been rationalized by the presence of heterogeneity in some firm individual characteristic mediating the export decision (Guerini et al., 2021). The literature identified either entry costs (Bernard et al., 2011; Mayer et al., 2014), future profits uncertainty (Impullitti et al., 2013) or internal financial condition (Assenza et al., 2016) as possible mediating factors.

${ }^{6}$ In this paper, with size we refer to firm sales.
} 
lection determines a high degree of turbulence in terms of market shares reallocation and entry and exit rates (Bartelsman et al., 2003; Bottazzi et al., 2010; Dosi et al., 2015). The turbulence affects in turn the age distribution of firms, which has been shown to be well approximated by an exponential law at different levels of aggregation (Coad, 2010b,a; Barba Navaretti et al., 2014; Coad, 2018). The process of entry and exit also affects export markets. Approximately, half of new exporters cease to export within the first year (see Eaton et al., 2008; Amador and Opromolla, 2013; Albornoz et al., 2012). At the same time, the firm export status is very persistent as approximately $90 \%$ of firms do not change it on a yearly basis (Bernard et al., 2003; Campa, 2004; Bernard and Jensen, 2004; Bernard and Wagner, 2001).

The literature has also pointed to firm idiosyncratic learning as a key determinant of the distribution of firm growth rates (see e.g. Olley and Pakes, 1996; Foster et al., 2001; Dosi, 2007; Dosi et al., 2017). In particular, empirical works have robustly shown that the firm growth rate distribution is leptokurtic and well approximated by a Laplace distribution (see Stanley et al., 1996; Bottazzi and Secchi, 2003, 2006a). Moreover, firm growth volatility is negatively correlated with size (see Hymer and Pashigian, 1962; Stanley et al., 1996; Sutton, 2002; Calvino et al., 2018). These two features are inconsistent with the Gibrat's Law of Proportionate Effects (Gibrat, 1931). ${ }^{7}$. Interestingly, the fattails property of growth rate distributions is robust to aggregation levels (Fu et al., 2005). Industry growth rates are also well approximated by a Laplace density (Castaldi and Sapio, 2008), as well as aggregate output growth rates (see Fagiolo et al., 2008; Castaldi and Dosi, 2009).

Fat-tails in the growth rate distributions at various aggregation levels imply that growth events that are larger in magnitude (either positive or negative) are statistically more relevant than what a Gaussian model would predict. This is very much related to the issue of growth rates volatility, which is a topic of primary concern in the policy debate (see e.g. Rodrik, 1998; Easterly et al., 2001). In this respect, recent contributions have studied the possible channels of transmission from micro to macro volatility (see for example Gabaix, 2011; Acemoglu et al., 2012; di Giovanni et al., 2014). Others have instead focused on the impact of international trade on volatility. In particular, some of the latter studies have found that exporters sales growth rate volatility is on average greater than

\footnotetext{
${ }^{7}$ Empirical estimates of the Gibrat's model suggest that the firm size coefficient is close to unity, as predicted by the law, but with strong deviations in the statistical properties of the residuals with respect to the Gibrat's law assumptions, especially when small firms are considered (Santarelli et al., 2006; Dosi and Nelson, 2010).
} 
non-exporters (Ćede et al., 2018; Vannoorenberghe, 2012). Furthermore the reallocation of market shares between foreign and domestic incumbents impacts the odds to grow or to shrink also at higher levels of aggregation (i.e. at industry and country levels, see di Giovanni and Levchenko, 2009, 2012; di Giovanni et al., 2019). This is because bilateral trade, firm intensive and extensive export margins are all positively associated to different degrees with trade openness (Bernard et al., 2011; Mayer and Ottaviano, 2008). In that respect, bilateral trade takes also place at both the country and the sector level (see the intra-industry trade findings in Balassa, 1966; Grubel and Lloyd, 1975; Fontagné and Freudenberg, 1997).

\begin{tabular}{|c|c|}
\hline \multicolumn{2}{|r|}{ Stylized Facts of Industry Dynamics } \\
\hline SF 1 & The volatility of industry sales is positively associated with trade openness \\
\hline SF 2 & The distribution of industry growth rates is tent-shaped and leptokurtic \\
\hline \multicolumn{2}{|r|}{ Stylized Facts of Intra-Industry Trade } \\
\hline SF 3 & Bilateral trade, firm intensive and extensive export margins are positively associated with trade openness \\
\hline SF 4 & Firms trade status are persistent \\
\hline SF 5 & A large share of new exporters ceases exporting within the year \\
\hline \multicolumn{2}{|r|}{ Stylized Facts of Firm Dynamics } \\
\hline SF 6 & The size distribution is more right skewed than a log-Normal law \\
\hline SF 7 & The growth rates distribution is tent-shaped and leptokurtic \\
\hline SF 8 & The volatility of firms growth rates is negatively associated with size \\
\hline SF 9 & The age distribution follows an exponential law \\
\hline SF 10 & The productivity distribution follows a log-Normal law \\
\hline \multicolumn{2}{|r|}{ Stylized Facts on Firms and International Trade } \\
\hline SF 11 & The productivity distributions of exporters and non exporters partially overlap \\
\hline SF 12 & The productivity of exporters is on average higher than the one of non exporters \\
\hline SF 13 & The size distributions of exporters and non exporters partially overlap \\
\hline SF 14 & The size volatility of exporters is on average higher that the one of non exporters \\
\hline SF 15 & Firm level exports are more right skewed than a log-Normal law \\
\hline SF 16 & The distribution of size for exporters looms larger with higher trade openness \\
\hline SF 17 & Exporters growth rate is on average more volatile than non-exporters growth rate \\
\hline SF 18 & Innovation activity is positively related to export performance \\
\hline
\end{tabular}

Table 1: Summary of the stylised facts of industrial dynamics and international trade at different levels of aggregation.

Table 1 summarizes the different stylized facts on international trade and industry and firm dynamics that we have discussed so far. The above statistical properties have had implications for the theoretical analysis of the mechanisms of market selection. However, except for the works in the evolutionary tradition (Nelson and Winter, 1982) the empirical insights on firm heterogeneity were mostly analyzed until the 2000 s by assuming perfectly competitive markets with fixed costs of entry and production (Jovanovic, 1982; Hopenhayn, 1992). The first contribution that models heteroge- 
neous agents in a monopolistic competition equilibrium is the work of Melitz (2003), which provides an intra-industry trade theory consistent with the evidence on exporters self-selection (Bernard and Jensen, 1995; Bernard and Bradford Jensen, 1999) and on the reallocation effects of trade liberalization (Pavcnik, 2002; Trefler, 2004). In Melitz model, firms take decisions on the basis of expected profits (as in Hopenhayn, 1992). More precisely, the firms serve each market that grants them nonnegative profits conditional on productivities and on the respective fixed costs. Productivities are heterogeneous, fixed in time and drawn from an exogenous general cumulative distribution function. As productivities are fixed, firms exit takes place exogenously with a constant probability. Trade liberalization induces a selection effect by generating two productivity thresholds in equilibrium, one for the domestic and one for the foreign market, under which the firm cannot cover the respective fixed costs. This leads to the two main results of the model. First, more productive firms become exporters, thereby generating an export productivity premium. Second, trade liberalization generates a selection effect. The productivity thresholds become higher and selection becomes thougher, implying the exit of firms with productivity lower than the new thresholds. In this context, new gains from trade arise in terms of higher aggregate productivity, that reduces price level and increases real wages by reallocating shares to more productive firms.

The research stream triggered by the work of Melitz (2003) is still very active and proved to be flexible enough able to explain additional stylised facts of trade and industry dynamics and to introduce new technical improvements. For instance, the Melitz model generates a Pareto distribution of size by assuming a Pareto distribution ${ }^{8}$ of firm productivity levels (see Baldwin, 2005; di Giovanni and Levchenko, 2012; Bernard et al., 2018). ${ }^{9}$

Differently from the class of models inspired by Melitz's wor, our model does not put particular emphasis on rationality and/or equilibrium and it shows how the main stylized facts on industry and trade dynamics can be generated by the interaction between simple mechanisms of firms learning

\footnotetext{
${ }^{8}$ The assumption of Pareto productivity, albeit at odds with empirical evidence (see Doms and Bartelsman, 2000), is necessary to provide a Pareto distributed size in equilibrium for two reasons. First, the Pareto distribution is scale invariant (i.e. truncated Pareto distribution remains Pareto distributed). This property is exploited by the works using the Melitz's framework because the equilibrium distribution of productivity is the assumed firm productivity distribution truncated by the cut-off productivity threshold above which it is optimal to produce. Second, size is proportional to productivity in monopolistic competition models, thus a Pareto size can only emerge from a Pareto productivity.

${ }^{9}$ Furthermore, the works of Atkeson and Burstein (2010) Burstein and Melitz (2011) and Impullitti et al. (2013) endogenously generates the Pareto productivity distribution by introducing a stochastic mechanisms of firms learning based on Luttmer (2007).
} 
and of market selection based on size and productivity. In this respect, our contribution is strongly rooted in the literature of stochastic models of firm dynamics (Gibrat, 1931; Simon, 1955; Ijiri and Simon, 1975) and in the evolutionary tradition (see Nelson and Winter, 1982). In particular, the industrial dynamics models of Dosi et al. $(1995,2017)$ are very close to ours in both the research questions and in the economic mechanisms considered, but they only focus on a closed economy. In addition, their mechanism of selection depends only on productivity while in our model selection is also mediated by firm's size. Finally our approach is also close to the one of the "balls and bins" model of Armenter and Koren (2014). However, differently from this work, we do not study multiproduct, multidestination exporters. We only focus on intra-industry trade. In addition, we put special emphasis on interplay between market selection and firm learning, which are instead absent in Armenter and Koren (2014).

\section{A model of intra-industry trade}

We now describe our dynamic model of intra-industry trade. The model features two countries, each populated by $N$ firms. Firms are heterogeneous in terms of productivity, which determines firm competitiveness. Firm productivity may change over time as a result of stochastic learning. In addition, each firm can compete in the domestic market and/or in the foreign one. The main mechanisms driving the model dynamics are market selection, firm learning and entry/exit processes. In the baseline version of the model that we present in the next section we abstract from firm idiosyncratic learning and from entry-exit. This abstraction allows us to obtain a full analytical description of the finite pairwise Pólya urn process for market selection. For simplicity, we begin by presenting the analytical properties of the process under autarchy. We then discuss the implications of the process in a two-countries setting with trade. Next, in Section 3.3 we develop the extended model including also firm learning and entry-exit of firms.

\subsection{Market Selection as a finite Pólya Urn Process: the baseline model}

Consider an industry populated by $N$ firms. Firms compete in a market characterized by a finite and time-constant number $M$ of market opportunities. Each opportunity has unitary size and the total 
number of opportunities corresponds to the total market size. In each period $t=1, \ldots, T$, a firm $i=1 \ldots, N$ is characterised by three state variables: size $s_{i, t} \in[0, M]$; market share $x_{i, t} \in[0,1]$, defined as the ratio between firm size and total market size; and productivity level (or "efficiency") $a_{i, t} \in \mathbb{R}^{+}$. In this baseline version of the model we assume that productivity is heterogeneous across firms and constant over time, so that $a_{i, t}=a_{i}>0 \forall t$. Productivities are randomly drawn from a distribution $G\left(a_{i}\right)$ with positive support. Firm size is measured by the number of market opportunities allocated to each firm $i$ in every period $t$. The sum of firm sizes is therefore constant over time and equal to total market size:

$$
M=\sum_{i=1}^{N} s_{i, t} \quad \forall t
$$

In every period $t$, firm size $s_{i, t}$ is determined as the outcome of a Pólya urn process. More precisely, $K>0$ pairs of firms are sequentially drawn (without replacement) with probability equal to their market shares and compete for the allocation of a market opportunity $k \in\{1, \ldots, K\}$. The most productive firm in the pair gains the market opportunity by stealing it from the least productive firm (which then decreases its size). Notice that the parameter $K$ also defines the number of market opportunities that are allocated at each time step. It thus captures the intensity of market competition. Let us suppose that firms have homogeneous size at time 0 , and let us denote initial size with $s_{i, 0}$. The law of motion of firm size resulting from the above competition process can be written as:

$$
s_{i, t+1}= \begin{cases}0 & \text { if } \sum_{\tau=0}^{t} \sum_{k=1}^{K} \xi_{i, k, \tau}=-s_{i, 0} \text { for } \tau \in[0, t] \\ s_{i, 0}+\sum_{\tau=0}^{t} \sum_{k=1}^{K} \xi_{i, k, \tau} & \text { if } \sum_{\tau=0}^{t} \sum_{k=1}^{K} \xi_{i, k, \tau} \in\left(-s_{i, 0}, M\right) \text { for } \tau \in[0, t] \\ M & \text { if } s_{i, 0}+\sum_{\tau=0}^{t} \sum_{k=1}^{K} \xi_{i, k, \tau}=M \text { for } \tau \in[0, t]\end{cases}
$$

where $\xi_{i, k, t}$ represents the size shock that a firm $i$ experiences at period $t$ when competing for the 
$k$ th opportunity. The shock $\xi_{i, k, t}$ is defined by:

$$
\xi_{i, k, t}= \begin{cases}z_{i j, t} & p_{i j, k, t} \forall j \neq i \\ 0 & 1-\sum_{\forall j \neq i} p_{i j, k, t}\end{cases}
$$

with

$$
z_{i j, t}=\left\{\begin{array}{lll}
+1 & \text { if } & a_{i}>a_{j} \\
-1 & \text { if } & a_{i}<a_{j}
\end{array}\right.
$$

where $p_{i j, k, t}$ is the probability that firm $i$ is drawn to compete with another firm $j$. The law of motion in (1) implies that size has at least two fixed points $(0$ and $M)$. The fixed point in 0 corresponds to the case in which a firm loses all its market share, the one in $\mathrm{M}$ to firm monopoly. Furthermore, the process of market reallocation generates a symmetric shock $\left(z_{i j, t}=-z_{j i, t}\right)$ to the size of the two firms in the pair. The most productive firm in the pair gets a positive shock of unitary size, wheres the least productive firm gets a negative shock, also of unitary size. Finally, with probability $1-\sum_{\forall j \neq i} p_{i j, k, t}$ a firm $i$ is not drawn in any pair and it does not change size at iteration $k .^{10}$

The probability that a firm $i$ is drawn together with firm $j$ at iteration $k, p_{i j, k, t}$, is increasing in the size of the two firms and it is defined by:

$$
p_{i j, k, t}=x_{i, k, t} \cdot x_{j \mid i, k, t}+x_{j, k, t} \cdot x_{i \mid j, k, t}
$$

where $x_{i, k, t}$ (respectively $x_{j, k, t}$ ) is the probability of drawing firm $i$ (resp. firm $j$ ) and $x_{j \mid i, k, t}$ (resp. $x_{i \mid j, k, t}$ ) is the probability of selecting its competitor (conditional on drawing the first firm without replacement). ${ }^{11}$ The latter probabilities are equal to firm market shares, and they read as:

\footnotetext{
${ }^{10}$ It is also important to highlight that the vector of firm efficiencies $a_{t}$ enters the model only as an ordinal measure by determining whether the firm $i$ wins the pairwise competition against $j$. It does not determine the size of the shock experienced by a firm, but only its sign.

${ }^{11}$ Notice that this definition of the matching probabilities excludes the possibility that the same firm $i$ is matched with herself.
} 


$$
\left\{\begin{aligned}
x_{i, k, t} & =\frac{s_{i, k, t}}{M} \\
x_{j \mid i, k, t} & =\frac{s_{j, k, t}}{M-s_{i, k, t}}
\end{aligned}\right.
$$

Where:

$$
s_{i, k, t}=s_{i, t-1}+\sum_{k=1}^{k} \xi_{i, k, t}
$$

The assumption that the probability of selecting a firm is increasing in firm market shares introduces dynamic increasing returns in the allocation of market opportunities. Bigger firms have a higher probability of being selected in order to compete with other firms. Moreover the resulting increase (or decrease) in market share immediately maps into $p_{i j, k, t}$, determining the increase (or decrease) in the odds to compete again. ${ }^{12}$

Finally, by combining equations (2), (4) and (5) with equation (1) we obtain that the average law of motion for firm size can be expressed as a multiplicative process:

$$
E\left(s_{i, k+1, t} \mid a_{t}\right)= \begin{cases}0 & \text { if } \quad s_{i, k, t}=0 \\ s_{i, k, t} \cdot\left(1+\frac{f_{i}\left(s_{k, t}, a_{t}\right)}{M}\right) & \text { if } \quad s_{i, k, t} \in(0, M) \\ M & \text { if } \quad s_{i, k, t}=M\end{cases}
$$

where $s_{k, t}$ is the size distribution at the $k$ th iteration of time $t, a_{t}$ the productivity distribution at time $t$ and the growth rate factor $f_{i}\left(s_{k, t}, a_{t}\right)$ is equal to:

$$
f_{i}\left(s_{k, t}, a_{t}\right)=\sum_{\forall j \neq i} z_{i, j, t}\left(1+\frac{M-s_{i, k, t}}{M-s_{j, k, t}}\right) x_{j \mid i, k, t}
$$

Thus, aside from the stationary states 0 and $M$, our model predicts that firm size is governed by a Gibrat-type dynamics (see Gibrat, 1931; Ijiri and Simon, 1975) where growth is proportional to current size. At the same time, and similar to other recent works in the industrial dynamics literature

\footnotetext{
${ }^{12}$ Moreover, such an allocation process breaks the i.i.d. characterization of the shocks that we would have if $p_{i j, k, t}$ was not updated, implying that the growth rate distribution cannot be generated by the Central Limit Theorem.
} 
(e.g. Bottazzi and Secchi, 2006a,b), our firm growth process departs in some important way from a standard Gibrat one, as firm size $s_{i, k, t}$ influences the firm growth rate by determining the probability that a firm is hit by a growth rate shock $z_{i, j, t}$. Moreover firm size determines the magnitude of the growth rate shock (captured by the ratio $\frac{M-s_{i, k, t}}{M-s_{j, k, t}}$ ).

\subsection{Asymptotic properties of market selection}

The market selection process described in the previous section implies that the firm with maximal productivity always experiences non-negative growth shocks as its market opportunities cannot be stolen by other firms. Intuitively, such a firm will asymptotically become the industry monopolist. This result is more rigorously stated by the next proposition.

Proposition 1. Consider a closed economy with a finite pairwise Pólya urn market allocation process and with a time-constant distribution of firm productivity levels $G\left(a_{i}\right)$. The market structure of this economy converges to monopoly as $K \rightarrow \infty$.

\section{Proof. See Appendix A}

The proof of the foregoing proposition is easy to understand in a 2-firms setting. If the same pair of firms is repeatedly drawn, the most productive firm will keep on stealing market opportunities from the least productive firm, that will eventually reach a zero size. This argument can easily be generalized to a $N$-firms setting. In such a framework the least productive firms will continuously lose market shares every time they are selected, eventually reaching a null size and thus a zero probability of being extracted. The firm that will converge faster to zero size is, on average, the least productive one. Once this happens, then the industry has only $N-1$ firms with positive size. The second least productive firm becomes now the least productive firm with positive market share, and it will lose market shares when selected. The process is reiterated until only one firm, i.e. the most productive firm, controls the whole market. ${ }^{13}$

Let us now introduce trade in the baseline model by considering a two-country setting with trade wherein $N$ domestic and $N$ foreign firms have the same initial size in every market as in Krugman (1979). The number of active firms in both markets is thus equal to $2 \cdot N$. Furthermore, we assume

\footnotetext{
${ }^{13}$ An equivalent result has been obtained in the finance literature by Blume and Easley (1992); Bottazzi and Giachini (2019) which have studied a stochastic process similar to the one analyzed here.
} 
that exporters' competitiveness in the foreign market is affected by an iceberg costs $0 \leq c \leq 1$ that decreases a firm productivity in the foreign market:

$$
\tilde{a}_{i, t}=a_{i, t}(1-c)
$$

where $\tilde{a}_{i, t}$ denotes the foreign efficiency of firm $i{ }^{14}$ The next proposition shows that, depending on the level of iceberg costs, market structure in the two countries can converge either to a domestic monopoly (where one firm absorbs all opportunities in the domestic market) or to an international monopoly (i.e. a situation where a single firm dominates markets in both countries).

Proposition 2. Consider a two-country economy with trade where market allocation is determined by a finite pairwise Pólya urn allocation process. Assume the two countries have identical firm productivity level distributions $G\left(a_{i, t}\right)$. Let $c \in[0,1]$ be the level of iceberg cost determining a firm foreign productivity according to Equation (9). The following asymptotic results hold as $K \rightarrow \infty$ :

1. if $c=0$ then the market structure of the two countries converges to an international monopoly

2. if $c \in(0,1)$, then the market structure of the two countries converges either to a domestic or to an international monopoly

3. if $c=1$ then the market structure of two countries converges to a domestic monopoly

Proof. See Appendix A

The case with zero iceberg cost in the above proposition $(c=0)$ corresponds to a situation where the two economies are perfectly integrated, and where they thus behave as a single market. In this case, as shown by Proposition 1 above, one firm will eventually absorb all market opportunties. When the iceberg cost is positive $(0<c<1)$, the international monopoly may arise or not and the probability of observing it depends on the level of the iceberg cost as well as on the moments of the productivity distribution (see also the proof of the proposition). Finally, when $c=1$ then a firm does not have any productive advantage when trading in the foreign market. In such a case the two

\footnotetext{
${ }^{14}$ Iceberg costs in our model are a proxy for the inverse of the degree of trade openness. They encompass both the traditional interpretation of geographical distance as well as the level of tariffs which can be applied to exported products.
} 
markets are completely separated and the finite Pólya urn market allocation process will generate local monopolies in both countries.

\subsection{Learning, entry-exit and selection: the extended model}

The asymptotic results presented in the previous section state that market allocation based on the finite pairwise Pólya process will generate either a local or an international monopoly depending on the level of iceberg cost. These results were however obtained assuming a static distribution of firm productivity levels. We now extend the two-country model to account for more realistic features. In particular, we introduce a process of firm technological learning that impacts on firm productivity and we allow for entry and exit of firms. We shall show that monopoly is not a limit market structure in this more general framework and that a more competitive industry emerges.

We model the learning process by following Dosi et al. $(1995,2017)$. Each incumbent firm increases its productivity according to a geometric random walk with non-negative productivity shocks. The law of motion of firm productivity is:

$$
a_{i, t}=a_{i, t-1}\left(1+\max \left\{0, \theta_{i, t}\right\}\right)
$$

where $\theta_{i, t}$ is a i.i.d. random shock that proxies for new available technological opportunities and that is drawn from a Beta distribution - i.e. $\theta \sim \mathcal{B}\left(\beta_{1}, \beta_{2}, \beta_{\min }, \beta_{\max }\right)$.

The learning process described by Equation (10) implies cumulativeness in learning (see Dosi, 1988) as firms improve upon their past efficiency level $a_{i, t} \cdot{ }^{15}$ Moreover, this process has two straightforward consequences for the dynamics of our model. First, it shifts to the right (and rescales) the whole distribution of firm productivity as time goes by. Second, it reshuffles the firm productivity rankings in each period, thus affecting firms odds to grow or shrink according to equation 2. These changes are sufficient to invalidate the results of Propositions 1 and 2, which depend on a time-constant productivity ranking of firms. ${ }^{16}$

Another difference with the baseline model is the presence of a variable number of firms in each

\footnotetext{
${ }^{15}$ In addition, productivity shocks in Equation (10) are non-negative as we assume that a firm is sufficiently rational not to transform the production process if the outcome of learning implies the adoption of a technique that is inferior to the old one.

${ }^{16}$ It is also worth noticing that, notwithstanding the absence of strictly negative productivity shocks in equation 10 , a positive efficiency shock, but smaller than average, might have a negative impact on firm competitiveness.
} 
market as a result of entry and exit. Exiting firms are firms whose market share in period $t$ is lower than a strictly positive threshold $\delta .{ }^{17}$ Exit from one market does not automatically imply the failure of a firm, as the same firm could still be active in the market of the other country. We assume that a firm fails whenever its market share is lower than $\delta$ in both markets. In addition, in each period $t$ firms that are not yet active in a market try to enter it by competing with incumbents according to the pairwise Pólya competition illustrated in the previous section. The pool of potential entrants is composed by foreign firms that are not yet present in the market as well as by domestic firms that exited previously.

Furthermore, entry in the model occurs also to replace failed firms. When a firm from country A goes bankrupt, a newborn firm belonging to the same country tries to enter by competing with incumbents. Similarly to Dosi et al. (2010, 2017), this newborn firm has an initial productivity level that is "copied" from the one of a randomly selected incumbent. ${ }^{18}$

Each potential entrant competes with an incumbent that is randomly selected with a probability proportional to its market share. Let $s_{j t}$ denote the size of the selected incumbent at time $t$. If the potential entrant has a higher productivity level than the incumbent then it actually enters in the market by stealing $\eta$ market opportunities from the incumbent, where $\eta$ is an integer drawn from a truncated Poisson distribution $P(\delta \cdot M)$ such that $1 \leq \eta \leq s_{j t .}{ }^{19}$

In each period, the following order of events takes place simultaneously in the domestic and the foreign markets:

1. incumbent firms update their productivity levels according to learning process described in Equation 10;

2. entry of new firms occurs;

3. firm market shares are reallocated;

4. exit of firms occurs.

\footnotetext{
${ }^{17}$ This is also consistent with the fixed cost mechanism of Melitz (2003) if one implicitly assumes that firms with $x_{i, t}<\delta$ are also unable to pay for these costs.

${ }^{18}$ The copied incumbent can be either a domestic or foreign firm. In the latter case the copied productivity level is discounted by a factor $\tau$ in order to capture the presence of limited knowledge spillovers across firms of different countries (see also Malerba and Nelson, 2011; Aghion et al., 2019)

${ }^{19}$ The foregoing competitive process for market entry avoids that new firms always enter with a size that is close to the exit threshold, something that would inflate firm exits and market turbulence in the model. Also notice that the mean of the Poisson distribution of entrants' market opportunities is equal to the exit threshold multiplied by market size. This allows us to match the empirical evidence that entrants have heterogeneous size, but are on average smaller than incumbents (Dunne et al., 1988; Geroski, 1995; Bartelsman et al., 2003).
} 


\section{Simulation results}

We have fully characterized the dynamics of the baseline model in an closed form. This is not feasible for the extended model with firm learning and firm entry-exit that we described in the previous section. We thus resort to Monte Carlo simulations for its analysis. ${ }^{20}$

Numerical simulations aim to show that the extended model is able to jointly reproduce the empirical evidence on industrial dynamics and international trade. We thus present our results in relation to the list of stylised facts described in section 2. We investigate the emergence of these stylized facts in relation to parameters of the model governing the market selection intensity and the level of trade openness. The first is captured by the number of pairwise interactions $K$, while the second is inversely related to the level of iceberg $\operatorname{costs} c$. In the next sections, and unless stated otherwise, we shall refer to these two parameters jointly as "the competition regime" Table 2 summarizes the different competition regimes we use in our Monte Carlo exercises, while Table 3 reports the value of the other parameters (and that are kept fixed in the various simulations exercises). Notice that our model features a relatively small number of parameters with respect to the large number of stylised facts that it aims to replicate. In addition, the model starts from a complete homogeneity condition, both in firm size and productivity (see also Table 3). Firm heterogeneity is therefore a fully endogenous property of the model. Finally, statistical tests of equality in means do not reject the assumption of equality between the results for the two countries. Thus, in what follows we report only the results for one economy.

\subsection{Competition and industry dynamics}

We begin by looking at the effects of competition regimes on variables related to market turbulence (see Table 4). These effects are well established in the trade and industry dynamics literature (see also Section 2) and their replication represents a first test of the empirical performance of our model. We observe that an increase in either selection intensity or trade openness increases exit rates as well as the turbulence index (measured as the total sum of the absolute changes in market shares). A key property of our model is that pairwise competition produces a reallocation of market op-

\footnotetext{
${ }^{20}$ In a Monte Carlo analysis the target statistics are computed as averages in multiple instances of the same model, with same parameters, but with different pseudo random draws. For a comparison between different scenarios instead, parameters are varied while the pseudo random draws are kept constant.
} 


\begin{tabular}{cccc}
\hline Parameters & \multicolumn{2}{c}{ Competition regimes } \\
\hline$K$ & $c$ & $\begin{array}{c}\text { Selection } \\
\text { Intensity }\end{array}$ & $\begin{array}{c}\text { Trade } \\
\text { Openness }\end{array}$ \\
\hline 500 & 0.5 & & Low \\
500 & 0.25 & Low & Medium \\
500 & 0 & & High \\
\hline 750 & 0.5 & & Low \\
750 & 0.25 & High & Medium \\
750 & 0 & & High \\
\hline \hline
\end{tabular}

Table 2: Competition regimes used in the Monte Carlo simulations.

\begin{tabular}{ccl}
\hline Parameters & Value & Description \\
\hline$N$ & 250 & Number of firms in each country \\
$T$ & 400 & Number of time steps \\
$\delta$ & 0.001 & Threshold market share \\
$s_{0}$ & 100 & Size at time 0 \\
$a_{0}$ & 1 & Productivity at time 0 \\
$\beta_{1}$ & 5 & Shape parameter of the learning shock \\
$\beta_{2}$ & 5 & Scale parameter of the learning shock \\
$\beta_{\min }$ & -0.25 & Minimal learning shock \\
$\beta_{\max }$ & 0.25 & Maximal learning shock \\
\hline \hline
\end{tabular}

Table 3: Model parametrization used in the Monte Carlo simulations.

portunities towards more productive firms. Increasing selection intensity or lowering iceberg costs clearly boosts the foregoing reallocation process. The result is that a higher share of inefficient (i.e. low productivity) firms is driven out of the market and that more productive firms become bigger. The latter process also results in higher levels of market concentration, measured by the HerfindahlHirschman index (cf. the third column Table 4). Accordingly, while one might expect that opening a closed economy would generate a more competitive market structure, our results suggest that this is not always the case (in line with the predictions of evolutionary models, see e.g. Dosi et al., 1995). ${ }^{21}$

\footnotetext{
${ }^{21}$ In addition to the results reported in Table 4 we have also investigated the degree of persistence in firm productivity levels emerging in our model. The learning mechanism in Eq. 10 implies a very high productivity persistence for firms that are already active in one market. At the same time, the overall degree of firm productivity persistence is affected
} 


\begin{tabular}{|c|c|c|c|c|c|c|}
\hline \multicolumn{2}{|c|}{ Competition regime } & \multicolumn{5}{|c|}{ Business and Industry Statistics } \\
\hline $\begin{array}{l}\text { Selection } \\
\text { intensity }\end{array}$ & $\begin{array}{l}\text { Trade } \\
\text { Openness }\end{array}$ & $\begin{array}{l}\text { Exit } \\
\text { Rate }\end{array}$ & $\begin{array}{l}\text { Turbulence } \\
\text { Index }\end{array}$ & $H H I$ & $\begin{array}{c}\text { Domestic Firms } \\
\text { Share }\end{array}$ & $\begin{array}{c}\text { Foreign Firms } \\
\text { Share }\end{array}$ \\
\hline \multirow{3}{*}{ Low } & Low & $\begin{array}{c}0.075 \\
(0.006)\end{array}$ & $\begin{array}{c}0.081 \\
(0.005)\end{array}$ & $\begin{array}{c}0.042 \\
(0.023)\end{array}$ & $\begin{array}{c}0.893 \\
(0.017)\end{array}$ & $\begin{array}{c}0.107 \\
(0.035)\end{array}$ \\
\hline & Medium & $\begin{array}{c}0.113 \\
(0.007)\end{array}$ & $\begin{array}{c}0.125 \\
(0.005)\end{array}$ & $\begin{array}{c}0.05 \\
(0.028)\end{array}$ & $\begin{array}{c}0.844 \\
(0.021)\end{array}$ & $\begin{array}{c}0.339 \\
(0.055)\end{array}$ \\
\hline & High & $\begin{array}{c}0.141 \\
(0.009)\end{array}$ & $\begin{array}{c}0.167 \\
(0.016)\end{array}$ & $\begin{array}{c}0.065 \\
(0.042)\end{array}$ & $\begin{array}{c}0.659 \\
(0.018)\end{array}$ & $\begin{array}{c}0.658 \\
(0.021)\end{array}$ \\
\hline \multirow{3}{*}{ High } & Low & $\begin{array}{c}0.091 \\
(0.007)\end{array}$ & $\begin{array}{c}0.1 \\
(0.005)\end{array}$ & $\begin{array}{c}0.052 \\
(0.027)\end{array}$ & $\begin{array}{c}0.858 \\
(0.017)\end{array}$ & $\begin{array}{c}0.068 \\
(0.033)\end{array}$ \\
\hline & Medium & $\begin{array}{c}0.133 \\
(0.006)\end{array}$ & $\begin{array}{c}0.145 \\
(0.005)\end{array}$ & $\begin{array}{c}0.056 \\
(0.025)\end{array}$ & $\begin{array}{c}0.817 \\
(0.022)\end{array}$ & $\begin{array}{c}0.274 \\
(0.049)\end{array}$ \\
\hline & High & $\begin{array}{c}0.165 \\
(0.008)\end{array}$ & $\begin{array}{c}0.202 \\
(0.018)\end{array}$ & $\begin{array}{c}0.06 \\
(0.031)\end{array}$ & $\begin{array}{c}0.627 \\
(0.017)\end{array}$ & $\begin{array}{c}0.621 \\
(0.019)\end{array}$ \\
\hline
\end{tabular}

Table 4: Exit Rate is the share of exiting firms on the total incumbents, Turbulence Index is the total sum of absolute change in market shares, HHI is the Hirschman-Herfindahl Index at the industry level, Domestic Firms Share and Foreign Firms Share are respectively the share of domestic and foreign incumbents with respect to the maximum number of firms in the market $(\mathrm{N})$. Standard errors in parentheses.

Next, we look at the effects of competition regimes on industry output volatility. The work of di Giovanni and Levchenko (2009) suggests that trade openness is positively correlated with industry growth rate since it increases the export opportunities for all the firms belonging to the industry (SF1 in Table 1). The results in the first column of Table 5 corroborate this evidence. We also fit the pooled sample of industry growth rates in a given scenario with an Exponential-Power distribution. Such a distribution is very flexible as it encompasses both the Normal distribution as well as the Laplace distribution characterized by fat tails (see Bottazzi and Secchi, 2006a; Fagiolo et al., 2008; Castaldi and Dosi, 2009). ${ }^{22}$. The second column of Table 5 indicates that the shape parameter (“b”) of the fitted Exponential-Power distributions is always below 2. Thus, regardless of the competition regime, our model generates industry growth rate distributions that deviate from the Normal benchmark and

by selection in our model, and in particular by the entry of newborn firms which replace failed ones. The results of our simulations show that firm productivity persistence varies little with competion regimes. This indicates that selection has a little impact on productivity persistence, which is then mostly explained by within firm learning in our model. The latter result is in line with a large amount of empirical evidence on firm productivity dynamics (Doms and Bartelsman, 2000; Dosi, 2007).

${ }^{22}$ More precisely, the Exponential-Power is a class of distributions with three parameters (mean, scale $(a)$ and shape (b)). The shape parameter $b$ is a proxy of thickness of the tails of the distribution, as it determines how fast the probability function approaches its extremes. The Normal and Laplace distributions, for example, are particular cases of the Exponential Power with $b=2$ and $b=1$ respectively. Thus we can discriminate between the goodness of their relative approximations by fitting an EP distribution. 

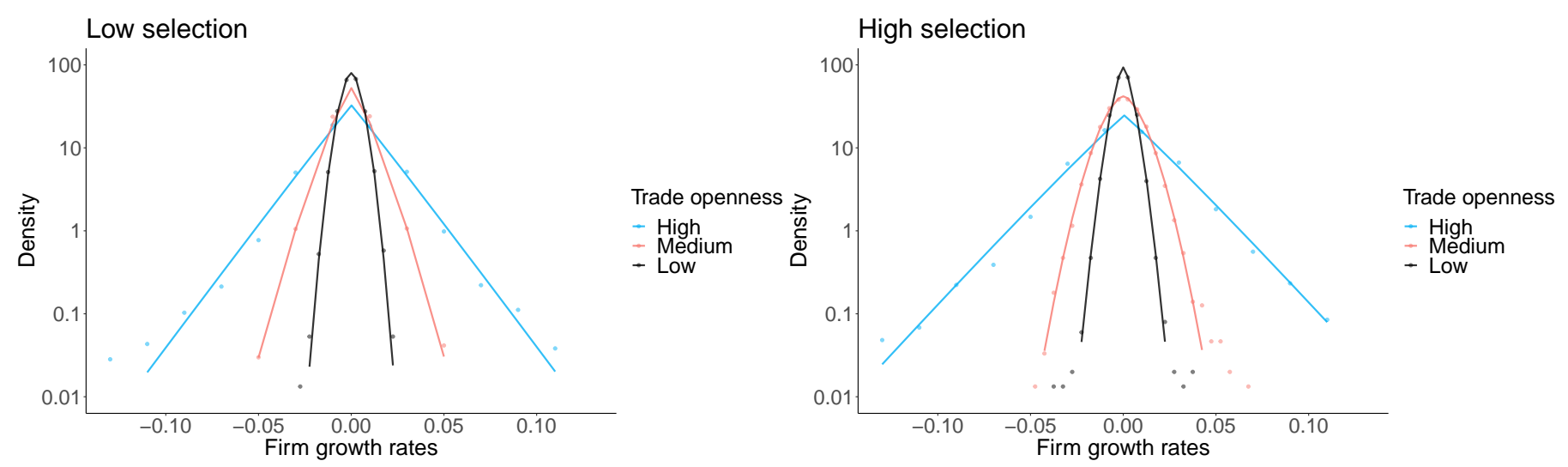

Figure 1: Pooled distribution of industry growth rate (points) and exponential power fit (line). The y-axis is in log-scale.

display fat-tails, in line with SF2 (see Table 1). Moreover, the shape parameter falls when trade openness increases and this effect is magnified by higher selection intensity. The value of the scale parameter - which is related to industry growth volatility - follows an opposite trend, as it increases with trade openness and selection intensity. These results are explained by the fact that a decrease in trade barriers removes the productivity gaps between domestic and foreign firms. This boosts the process of reallocation of market shares among firms, thus generating more volatile and more leptokurtic industry growth rate distributions.

\begin{tabular}{llccc}
\hline Competition regime & \multicolumn{3}{c}{ Exponential Power Fit } \\
\hline $\begin{array}{l}\text { Selection } \\
\text { Intensity }\end{array}$ & $\begin{array}{l}\text { Trade } \\
\text { Openness }\end{array}$ & $\begin{array}{c}\text { Average } \\
\text { Volatility }\end{array}$ & $b$ & $a$ \\
\hline & Low & $\begin{array}{c}0.005 \\
(0.001)\end{array}$ & 1.806 & 0.005 \\
Low & Medium & $\begin{array}{c}0.01 \\
(0.002)\end{array}$ & 1.268 & 0.010 \\
& High & $\begin{array}{c}0.02 \\
(0.011)\end{array}$ & 1.022 & 0.021 \\
& Low & $\begin{array}{c}0.005 \\
(0.001)\end{array}$ & 1.526 & 0.005 \\
High & Medium & $\begin{array}{c}0.01 \\
(0.002)\end{array}$ & \\
& & 0.026 & 1.691 & 0.010 \\
& High & $(0.009)$ & & \\
& & & \\
\hline \hline
\end{tabular}

Table 5: Monte Carlo average of the growth rate volatility of industry output And fitted Exponential-Power parameters. $b$ and $a$ are respectively the shape and scale parameters. 


\subsection{Competition and intra-industry trade}

Competition regimes also impact on the characteristics of the population of active firms in a market. The last two columns of Table 4 indicate that when trade openness is low almost all the incumbents are domestic firms. When openness is high instead incumbents are evenly spread between domestic and foreign firms. Overall, our model produces a monotonic increasing (decreasing) relation between trade openness and the presence of foreign (domestic) incumbents in a market.

\begin{tabular}{|c|c|c|c|c|c|c|c|}
\hline \multicolumn{2}{|c|}{ Competition regime } & \multicolumn{2}{|c|}{ Export Margins } & \multicolumn{2}{|c|}{ Intra-Industry Trade } & \multicolumn{2}{|c|}{ Export Flows } \\
\hline $\begin{array}{l}\text { Selection } \\
\text { Intensity }\end{array}$ & $\begin{array}{l}\text { Trade } \\
\text { Openness }\end{array}$ & Extensive & Intensive & $\begin{array}{c}\text { Bilateral } \\
\text { Trade }\end{array}$ & $\begin{array}{l}\text { Grubel-Lloyd } \\
\text { Index }\end{array}$ & Mean & St. Deviation \\
\hline \multirow{3}{*}{ Low } & Low & $\begin{array}{c}0.1 \\
(0.036)\end{array}$ & $\begin{array}{l}28.818 \\
(1.818)\end{array}$ & $\begin{array}{c}0.031 \\
(0.008)\end{array}$ & $\begin{array}{c}0.674 \\
(0.112)\end{array}$ & $\begin{array}{c}0.03 \\
(0.013)\end{array}$ & $\begin{array}{c}0.013 \\
(0.009)\end{array}$ \\
\hline & Medium & $\begin{array}{c}0.333 \\
(0.055)\end{array}$ & $\begin{array}{c}40.777 \\
(13.058)\end{array}$ & $\begin{array}{c}0.137 \\
(0.018)\end{array}$ & $\begin{array}{c}0.73 \\
(0.11)\end{array}$ & $\begin{array}{c}0.136 \\
(0.038)\end{array}$ & $\begin{array}{c}0.04 \\
(0.026)\end{array}$ \\
\hline & High & $\begin{array}{c}0.659 \\
(0.024)\end{array}$ & $\begin{array}{c}75.29 \\
(12.776)\end{array}$ & $\begin{array}{c}0.48 \\
(0.01)\end{array}$ & $\begin{array}{c}0.84 \\
(0.056)\end{array}$ & $\begin{array}{l}0.488 \\
(0.06)\end{array}$ & $\begin{array}{c}0.076 \\
(0.029)\end{array}$ \\
\hline \multirow{3}{*}{ High } & Low & $\begin{array}{c}0.067 \\
(0.027)\end{array}$ & $\begin{array}{c}27.99 \\
(1.694)\end{array}$ & $\begin{array}{c}0.019 \\
(0.008)\end{array}$ & $\begin{array}{c}0.641 \\
(0.112)\end{array}$ & $\begin{array}{c}0.019 \\
(0.009)\end{array}$ & $\begin{array}{c}0.01 \\
(0.006)\end{array}$ \\
\hline & Medium & $\begin{array}{c}0.274 \\
(0.051)\end{array}$ & $\begin{array}{l}37.821 \\
(5.133)\end{array}$ & $\begin{array}{c}0.106 \\
(0.015)\end{array}$ & $\begin{array}{c}0.708 \\
(0.108)\end{array}$ & $\begin{array}{l}0.106 \\
(0.03)\end{array}$ & $\begin{array}{c}0.037 \\
(0.017)\end{array}$ \\
\hline & High & $\begin{array}{c}0.62 \\
(0.022)\end{array}$ & $\begin{array}{c}75.609 \\
(11.119)\end{array}$ & $\begin{array}{c}0.476 \\
(0.011)\end{array}$ & $\begin{array}{c}0.825 \\
(0.054)\end{array}$ & $\begin{array}{c}0.464 \\
(0.059)\end{array}$ & $\begin{array}{c}0.084 \\
(0.025)\end{array}$ \\
\hline
\end{tabular}

Table 6: Margins, bilateral and intra-industry trade for different competition regimes. Standard errors in parentheses. The extensive margin is defined as the share of exporters, the intensive margin in terms of average exported sales per firm. The bilateral trade is the total bilateral export divided the world total production. Export flows are defined as the export share on the total country production.

Table 6 takes a deeper look at the trade dynamics emerging in our model by reporting statistics on export margins, intra-industry trade (Balassa, 1966; Grubel and Lloyd, 1975) and trade flows in different competition regimes. In line with empirical evidence (cf. SF3 in Table 1), the extensive margin (firm participation in foreign markets), the intensive margin (the average firm-level export flow) as well as the measures of bilateral intra-industry trade flows are all positively related to trade openness data. When barriers to trade decrease, more firms export, and they export more (see Table 6). Accordingly, the bilateral trade flows increase on average and they become more volatile (cf. the last two columns of the table). This is coherent with the stream of empirical literature which has shown the existence of a inverse relation between country-level distance (which reflects 
entry barriers in the foreign markets) and foreign market participation or intra-industry trade flows (Bernard et al., 2011, 2012). However, notice the share of exporting firms is barely $60 \%$ in regimes with high openness, which indicates that more than $1 / 3$ of firms are excluded from participating to the export market. These excluded firms are low productivity firms that are unable to enter foreign markets as they are outperformed by bigger and more productive domestic and foreign incumbents.

We also investigate how competition regimes affect the export status and the probability of survival in foreign markets. Table 7 reveals that our model generates a very persistent export status (see SF4). Moreover, export persistence decreases with openness, hinting at a higher turbulence in presence of more trade flows. Table 7 also indicates that the share of exporting firms is pretty high and invariant across competition regimes. In constrast, less than half of new exporters survive after the first year of entry in the foreign market (in line with SF5) and the probability of survival marginally decreases with stronger selection. The latter two results are inherent to the strong competitive pressure a firm is subject to when it enters a foreign market. Indeed, the pairwise selection process we introduced in Section 3.3 implies that foreign entrants will typically compete with bigger and thus more productive firms, at the time of their entry in the market but also afterwards. It follows that only a small fraction of those potential entrants, i.e. those with high productivity, will be able to outperform incumbents and acquire a stable presence in the foreign market.

Finally, the work of Bernard et al. (2009) decomposes the rate of change of export activity and finds that the intensive margin plays a more relevant role over the extensive one. Our simulations data allows us to verify whether this claim holds true in our model. The results in Table 8 confirm the findings of Bernard et al. (2009), in that our model predicts that intensive margin is more important than the extensive one only when trade openness is maximal (i.e. when iceberg costs are null). With a positive iceberg cost instead (i.e. in the "Low" and "Medium" openness scenarios), the extensive margin effect dominates the intensive margin one. Such results are also coherent with the work of Eaton et al. (2011), which finds that the intensive margin dominates the extensive one in presence of a fall in trade barriers. 


\begin{tabular}{llccc}
\hline Competition Regime & \multicolumn{3}{c}{ Export Status } \\
\hline $\begin{array}{l}\text { Selection } \\
\text { Intensity }\end{array}$ & $\begin{array}{l}\text { Trade } \\
\text { Openness }\end{array}$ & $\begin{array}{c}\text { Export Status } \\
\text { Persistence }\end{array}$ & $\begin{array}{c}\text { New Exporters } \\
\text { Survival }\end{array}$ & $\begin{array}{c}\text { All Exporters } \\
\text { Survival }\end{array}$ \\
\hline & Low & $\begin{array}{c}0.946 \\
(0.02)\end{array}$ & $\begin{array}{c}0.427 \\
(0.037)\end{array}$ & $\begin{array}{c}0.878 \\
(0.022)\end{array}$ \\
Low & Medium & $\begin{array}{c}0.861 \\
(0.024)\end{array}$ & $\begin{array}{c}0.433 \\
(0.022)\end{array}$ & 0.852 \\
& & 0.773 & $0.012)$ \\
& High & $(0.013)$ & $(0.014)$ & 0.867 \\
& & 0.952 & 0.386 & $0.008)$ \\
& Low & $(0.022)$ & $(0.043)$ & $(0.035)$ \\
& & 0.848 & 0.404 & 0.834 \\
High & Medium & $(0.025)$ & $(0.018)$ & $(0.012)$ \\
& & 0.741 & 0.439 & 0.851 \\
& High & $(0.012)$ & $(0.015)$ & $(0.007)$ \\
\hline \hline
\end{tabular}

Table 7: Model-generated statistics on export persistence and survival. Export Status Persistence is the Monte Carlo average of the share of incumbents whose export status does not change from one period to the other. New Exporters Survival is the share of newly exporting firms that survive after the first year. All Exporters Survival is the share of exporters that survives from one period to the other.

\subsection{Statistical properties of firm size, growth and age distributions}

The results discussed in the previous section document how our model predicts an increase in exit rates and in market turbulence when competitive pressures are higher. We now turn to analyze how the model fares in reproducing the main statistical properties concerning the firm size, growth and age distributions. The empirical evidence discussed in Section 2 indicates that firms not only display wide asymetries in productivity levels. They also remarkably differ in their sizes at every level of aggregation. In particular, several studies have pointed out that the size distribution of firms is characterized by a leptokurtic right tail, fatter than the one produced by a log-Normal distribution (cf. SF6 in Table 1). Figure 2 shows that our model reproduces this property. The pooled distributions of firm sizes generated from our model deviate from the Log-normal in all competition regimes we consider.

Dynamic increasing returns in firm selection explain the shape of the size distribution. The Pólya urn selection mechanism implies that bigger and more productive firms are more likely to attract market opportunities and to grow. We also estimate the tail exponent of the distribution and we find that the hypothesis that the firm size distribution is a Pareto is not rejected in any scenario analyzed 


\begin{tabular}{|c|c|c|c|c|}
\hline \multicolumn{2}{|c|}{ Competition Regime } & \multicolumn{3}{|c|}{ Export Margins } \\
\hline $\begin{array}{l}\text { Selection } \\
\text { Intensity }\end{array}$ & $\begin{array}{l}\text { Trade } \\
\text { Openness }\end{array}$ & T\% & Ratio & $\%$ Ratio $>1$ \\
\hline \multirow{3}{*}{ Low } & Low & $\begin{array}{l}0.072 \\
(0.02)\end{array}$ & $\begin{array}{c}0.118 \\
(0.021)\end{array}$ & 0 \\
\hline & Medium & $\begin{array}{c}0.208 \\
(0.047)\end{array}$ & $\begin{array}{c}0.361 \\
(0.131)\end{array}$ & 1 \\
\hline & High & $\begin{array}{c}0.563 \\
(0.044)\end{array}$ & $\begin{array}{c}1.261 \\
(0.182)\end{array}$ & 95 \\
\hline \multirow{3}{*}{ High } & Low & $\begin{array}{c}0.072 \\
(0.017)\end{array}$ & $\begin{array}{l}0.114 \\
(0.02)\end{array}$ & 0 \\
\hline & Mild & $\begin{array}{c}0.203 \\
(0.057)\end{array}$ & $\begin{array}{c}0.353 \\
(0.124)\end{array}$ & 0 \\
\hline & High & $\begin{array}{c}0.602 \\
(0.047)\end{array}$ & $\begin{array}{c}1.426 \\
(0.204)\end{array}$ & 100 \\
\hline
\end{tabular}

Table 8: The decomposition of the total export in the contribution from the extensive and the intensive margin. $T \%$ is the percentage of time step in which the intensive was greater than the extensive margin, Ratio is the average ratio of intensive to extensive margin, $\%$ Ratio $>1$ is the percentage of times in which the ratio is greater than 1 across simulations.

(see Table 9). ${ }^{23}$ In addition, most fitted coefficients in Table 9 are smaller than 3. This indicates that relative differences in firm size are so wide that only the first and the second moments of the distribution exist.

Increasing returns also generate Laplace-like firm growth rate distributions (see SF6 of Table 1) in our model. See Figure 3. As firms do not have the same probability to compete for market opportunities, size shocks are not identically distributed across firms. Since what is gained by a firm is lost by another in the model, shocks are not independently distributed as well. These two properties entails a violation of the i.i.d. distribution of shocks that would instead generate a Normal distribution of firm growth rates because of the Central Limit Theorem (see also Fu et al., 2005; Bottazzi and Secchi, 2003, 2006a, for an explanation of Laplace distributed firm growth rates along the same lines). Furthermore, Figure 3 also shows that an increase in trade openness increases firm volatility. The Laplace distributions of firm growth rates are more dispersed when openness is higher and this results holds irrespectively of the selection intensity. Thus, the effect of removing trade barriers on volatility, that we already spotted at the industry level in Section 4.1, is also replicated at the firm

\footnotetext{
${ }^{23}$ The Pareto fit is tested statistically by means of the test of Clauset et al. (2009), that builds upon a KolmogorovSmirnov test.
} 

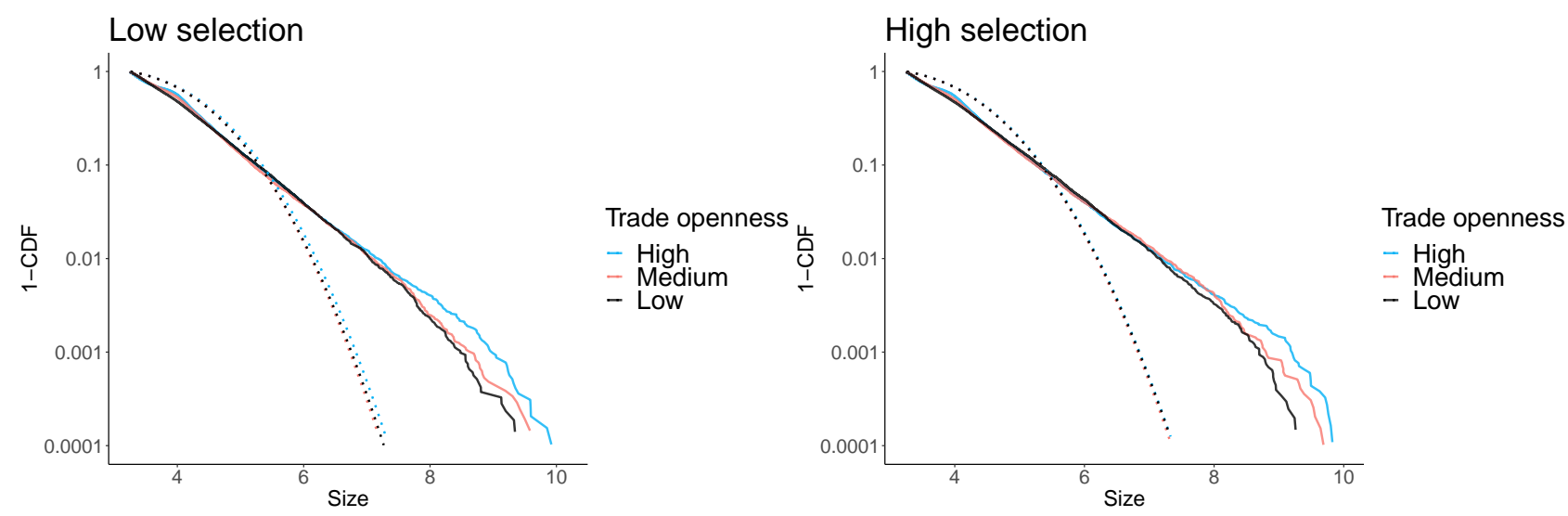

Figure 2: Log-centred size distribution (lines) and fitted log-Normal distribution (dots) across trade regimes. Size is the sum of domestic and foreign sales. Results are pooled over Monte Carlo simulations.

\begin{tabular}{llccccc}
\hline Competition Regime & \multicolumn{5}{c}{ Pareto Estimates } \\
\hline $\begin{array}{l}\text { Selection } \\
\text { Intensity }\end{array}$ & $\begin{array}{l}\text { Trade } \\
\text { Openness }\end{array}$ & Aggregate & $e^{5}$ & $e^{6}$ & $e^{7}$ & $e^{8}$ \\
\hline \multirow{2}{*}{ Low } & Low & 2.249 & 2.272 & 2.349 & 2.627 & 3.052 \\
& Medium & 2.349 & 2.273 & 2.271 & 2.426 & 2.685 \\
& High & 2.244 & 2.240 & 2.205 & 2.273 & 2.531 \\
\hline \multirow{2}{*}{ High } & Low & 2.203 & 2.237 & 2.322 & 2.460 & 2.925 \\
& Medium & 2.227 & 2.187 & 2.148 & 2.342 & 2.978 \\
& High & 2.244 & 2.217 & 2.175 & 2.215 & 2.326 \\
\hline \hline
\end{tabular}

Table 9: The fitted coefficient $\alpha$ of the Pareto distribution $P(x)=x^{-\alpha}$ for the aggregate empirical distribution of firm size and for different cut-off points of the empirical distribution $\left(\left\{e^{5}, e^{6}, e^{7}, e^{8}\right\}\right.$ corresponding to $\{5,6,7,8\}$ in Figure 2). The Pareto distributions were fittedby using the procedure described in Clauset et al. (2009). It is not possible to reject a Pareto fit at the 5\% confidence level for all Pareto estimates.

level. This effect is explained by the increase in the number of market opportunities that higher trade openness allows to compete for. When trade barriers are lower firms can enter more easily in foreign markets and thus attract not only domestic but also foreign market opportunities. This increases their growth potential (both positively and negatively).

Firm growth volatility is also inversely related to firm size (see SF8 in Table 1). This implies that smaller firms are more likely to experiment very high or very low growth rates. Our model is able to replicate this stylised fact, which is depicted in Figure 4). The linear fit in the log-log space approximates fairly well the relations in the different competition regimes and do not change when considering the regression on pooled data or the Monte Carlo average coefficient of the regression (Table 10). The relation shifts upward and the slope increases when the market selection strengthens 

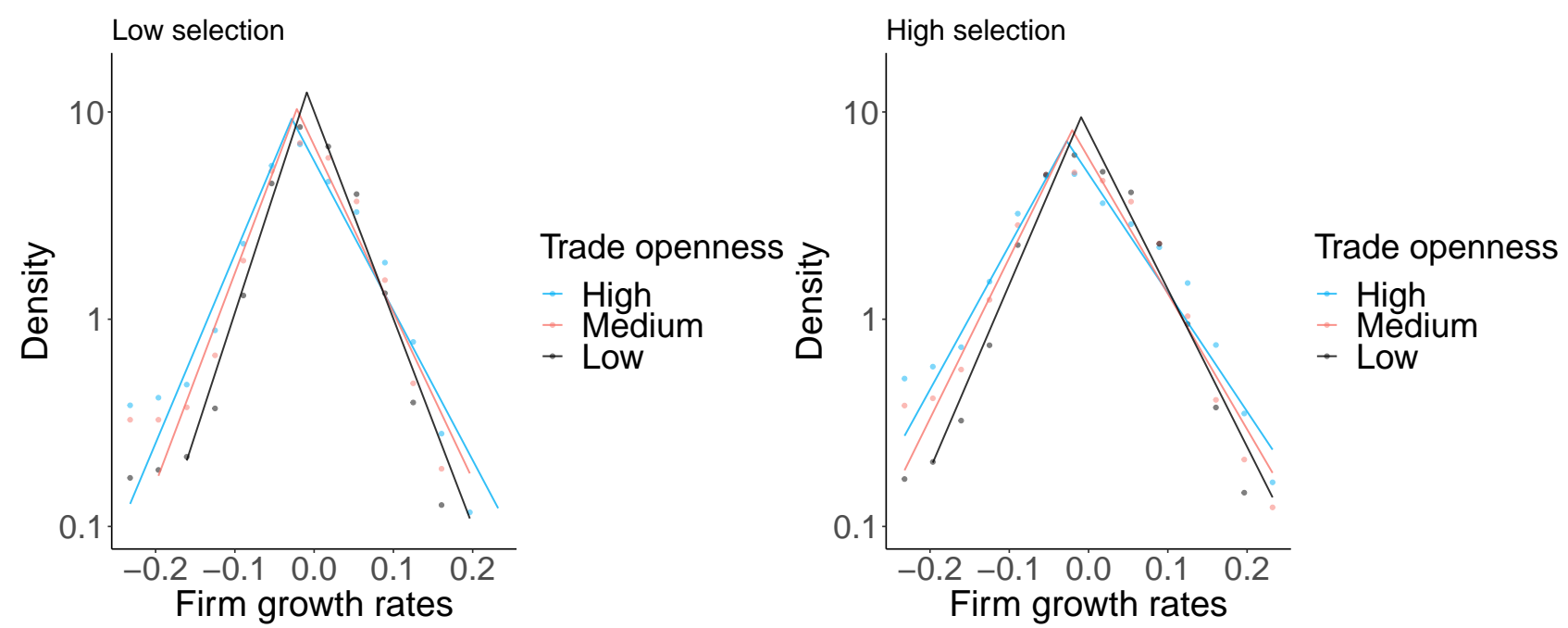

Figure 3: Pooled growth rates distribution with Laplace distribution fit across competition regimes. The y-axis is in log-scale.

and when trade openness gets higher. ${ }^{24}$

\section{Low selection}

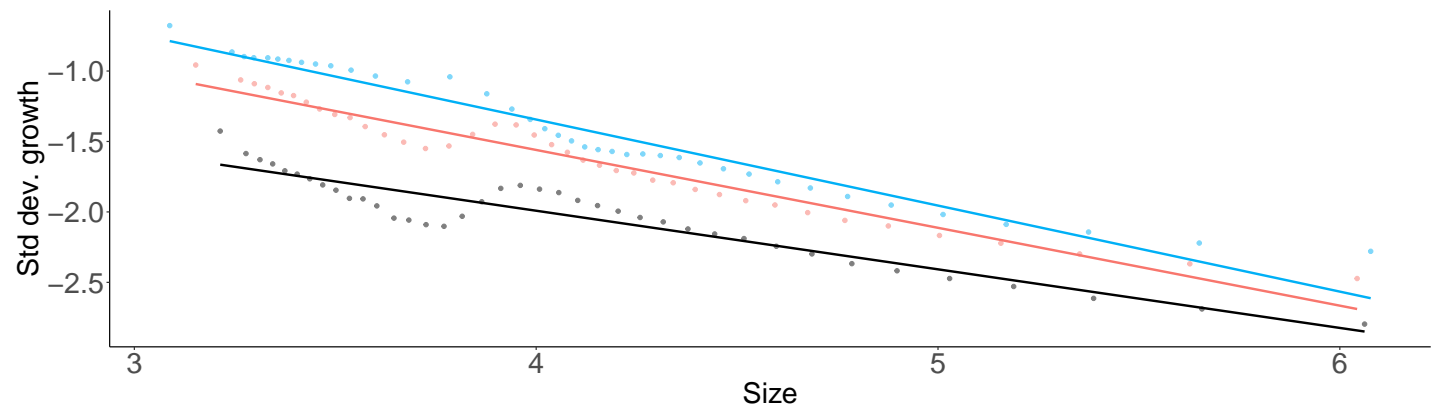

Trade openness

- High

- Medium

- Low

High selection

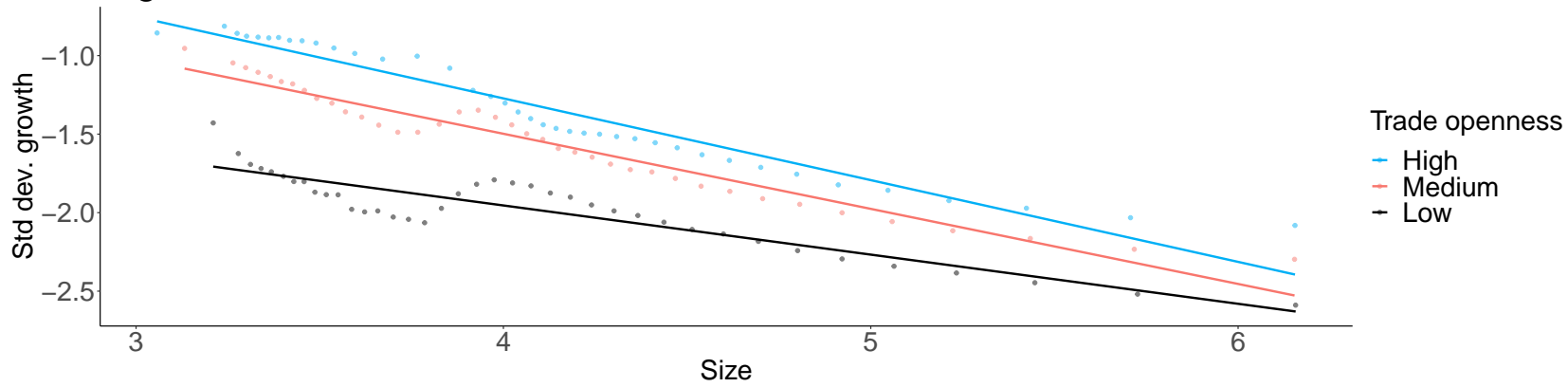

Figure 4: Scaling growth variance relation with fitted binned linear regression across trade regimes. Data points have been computed on equally sized bins of firm growth and size. Both the $\mathrm{x}$ and the $\mathrm{y}$-axis are in log-scale.

Finally, our model is also able to reproduce an age distribution of firms that is exponentially

\footnotetext{
${ }^{24}$ The above documented inverse relation between firm growth rates and firm size is often considered as a violation of the Gibrat's Law of Proportionate Effects, which predicts the independence of firm growth rates from firm size (see Dosi, 2007). The violation of the Gibrat's law in our model should not surprise because, as we already mentioned, growth shocks are by construction not independent in our model. The gain of a market opportunity by one firm directly corresponds to a loss for another one. As a further robustness check on the violation of the Gibrat's law we have estimated several independent Gibrat regressions in all competition regimes we consider. The null hypothesis that the regression coefficient of firm size is 1 is rejected in most cases.
} 


\begin{tabular}{|c|c|c|c|c|c|c|}
\hline \multicolumn{2}{|c|}{ Competition Regime } & \multicolumn{2}{|c|}{ Pooled OLS } & \multicolumn{3}{|c|}{ Monte Carlo OLS } \\
\hline Selection & Trade & & & & & \\
\hline Intensity & Openness & $\hat{\beta}$ & $R^{2}$ & $\hat{\bar{\beta}}$ & $\bar{R}^{2}$ & $\%$ rej. $H_{0}$ \\
\hline \multirow{3}{*}{ Low } & Low & $\begin{array}{c}-0.416 \\
(0.025)\end{array}$ & 0.876 & $\begin{array}{l}-0.386 \\
(0.092)\end{array}$ & 0.664 & 1 \\
\hline & Medium & $\begin{array}{l}-0.553 \\
(0.02)\end{array}$ & 0.955 & $\begin{array}{c}-0.533 \\
(0.066)\end{array}$ & 0.896 & 1 \\
\hline & High & $\begin{array}{c}-0.611 \\
(0.022)\end{array}$ & 0.954 & $\begin{array}{c}-0.583 \\
(0.036)\end{array}$ & 0.911 & 1 \\
\hline \multirow{3}{*}{ High } & Low & $\begin{array}{c}-0.313 \\
(0.024)\end{array}$ & 0.822 & $\begin{array}{l}-0.279 \\
(0.104)\end{array}$ & 0.544 & 0.96 \\
\hline & Medium & $\begin{array}{c}-0.478 \\
(0.018)\end{array}$ & 0.949 & $\begin{array}{c}-0.462 \\
(0.049)\end{array}$ & 0.891 & 1 \\
\hline & High & $\begin{array}{c}-0.521 \\
(0.021)\end{array}$ & 0.941 & $\begin{array}{l}-0.503 \\
(0.032)\end{array}$ & 0.896 & 1 \\
\hline
\end{tabular}

The ${ }^{*}$ indicates significance at $0.1 \%$ confidence level. $H_{0}: \hat{\beta}=0$.

Table 10: Estimated coefficient and $R^{2}$ for the linear regression fitted to the binned points of the scaling growth variance relation of Figure 4 (columns 1 and 2) and Monte Carlo averages of the coefficient and of the $R^{2}$ from the regression fit at the end of every simulation (columns 3 and 4). The null hypothesis of independence between size and growth rate standard deviation (null fitted coefficient) is always refused (column 5).

distributed as highlighted by (Calvino et al., 2020, cf. SF9). See Figure 5. The exponent of the distribution, estimated with a log-log regression relating numerosity to age, is negative and it decreases with the level of competition (see Table 11). Higher competition also exerts a positive influence on the rate of exit (cfr. Table 4) and thus affects the slope of the age distribution.
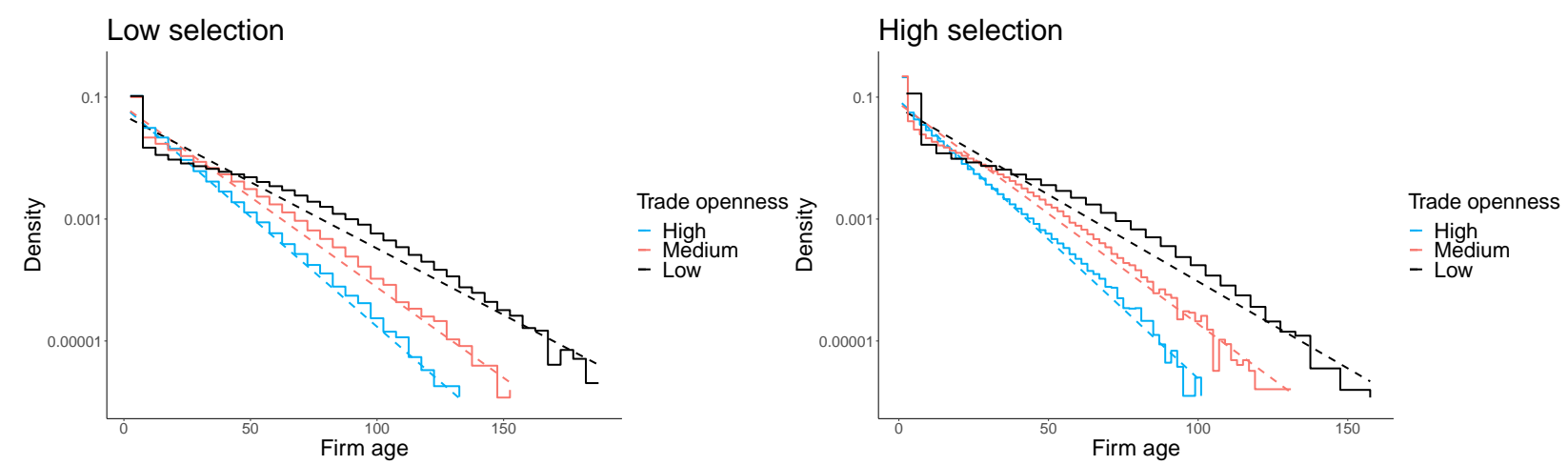

Figure 5: Pooled distribution of firm-level age across different regimes with fitted exponential distributions (the dashed lines). The $y$-axis is in $\log$ scale. 


\begin{tabular}{lllc}
\hline \multicolumn{2}{l}{ Competition Regime } & \multicolumn{2}{c}{ Firm Age Regression } \\
\hline $\begin{array}{l}\text { Selection } \\
\text { Intensity }\end{array}$ & $\begin{array}{l}\text { Trade } \\
\text { Openness }\end{array}$ & $\beta$ & $R^{2}$ \\
\hline \multirow{2}{*}{ Low } & Low & -0.05 & 0.97 \\
& Medium & -0.068 & 0.987 \\
& High & -0.083 & 0.996 \\
\hline \multirow{3}{*}{ High } & Low & -0.066 & 0.97 \\
& Medium & -0.083 & 0.984 \\
& High & -0.105 & 0.99 \\
\hline \hline
\end{tabular}

All estimates are significance at the $0.1 \%$ confidence level.

Table 11: Estimated coefficient and $R^{2}$ for the log-log linear model relating the numerosity of each firm age profile to firm age values. These numbers represent the slope and the quality of the dashed lines fitted in Figure 5.

\subsection{Firms in international trade}

We complete our study by focusing on the ability of the model to reproduce the stylized facts relating to the characteristics of exporting and non-exporting firms. Figure 6 shows the kernel density of firm productivity levels (rescaled by the industry mean) in the six different competition regimes we consider. In line with empirical evidence (see SF10 in Table 1) our model endogenously generates a productivity distribution which is Log-Normal and thus characterised by right-skewness. This is an indication of the presence of wide productivity differentials between the firms. Moreover, as in Melitz (2003), we observe a clear selection effect following an increases in trade openness. High trade barriers (low trade openness) generate more dispersed productivity distributions. They also generate fatter right tails (see Figure 6 and Table 12).
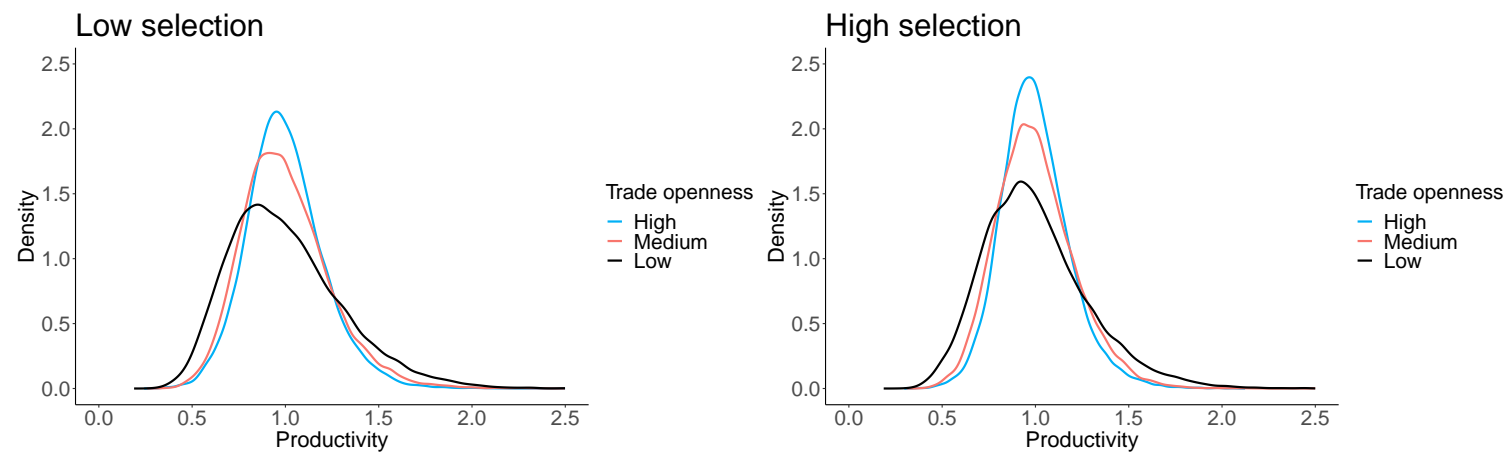

Figure 6: Kernels densities of firm productivity levels across competition regimes regimes. The densities are computed on the sample of firm productivity levels pooled over Monte Carlo simulations and normalized by the average productivity level. 


\begin{tabular}{llccc}
\hline \multicolumn{2}{c}{ Competition Regime } & \multicolumn{3}{c}{ Distribution Moments } \\
\hline $\begin{array}{l}\text { Selection } \\
\text { Intensity }\end{array}$ & $\begin{array}{l}\text { Trade } \\
\text { Openness }\end{array}$ & Std. Dev. & Skewness & Kurtosis \\
\hline \multirow{2}{*}{ Low } & Low & 0.304 & 0.79 & 3.833 \\
& Medium & 0.235 & 0.743 & 4.287 \\
& High & 0.207 & 0.546 & 4.192 \\
\hline \multirow{3}{*}{ High } & Low & 0.28 & 0.765 & 3.944 \\
& Medium & 0.211 & 0.594 & 4.062 \\
& High & 0.185 & 0.572 & 4.186 \\
\hline \hline
\end{tabular}

Table 12: Standard deviation, skewness and kurtosis of the distribution of firm productivity levels (rescaled by the industry mean). Results are pooled over Monte Carlo simulations.

Furthermore, coherently with SF12, our model predicts that exporters are not a random subgroup of all firms in terms of productivity. Figure 7 shows that exporters are on average more productive than non-exporters in all competition regimes. However, the two distributions of exporters and non-exporters overlap, which indicates that high-productivity non-exporters co-exist with lowproductivity exporters (cf. SF11). The foregoing properties are usually explained on the grounds of imperfect self-selection or unobserved heterogeneity at the firm level (e.g. because entry costs or financial constraints, see Impullitti et al., 2013; Mayer et al., 2014; Assenza et al., 2016; Guerini et al., 2021). Our model instead generates them from the interaction between imperfect market selection and firm learning. First, the existence of trade barriers and the fact that market selection rewards more productive firms implies that entry in foreign market depends on a productivity premium. Second, firm productivity changes over time because of learning. Third, firms are selected to compete on their basis of their size, not of their productivity. This three features imply that foreign firms whose productivity increases more relative to other firms in the market gain further market shares and thus participate more to the process of reallocation of market opportunities. In contrast, foreign entrants whose productivity grows relatively less will keep small but stable market shares because they will not be selected for the reallocation of further market opportunities.

The above considerations also help to understand how the two distributions of exporters and non-exporters change across competition regimes. Higher trade barriers increase the average productivity premium of exporters and contribute to widen the gap between the distribution of ex- 
porters and non-exporters (cf. the plots Figure 7 from right to left). This is explained by the fact that when trade barriers - and so iceberg costs - are high, less efficient firms have more difficulties in entering foreign markets. Indeed, a low efficiency firm already has a low likelihood of winning the pairwise match with another incumbent firm. When iceberg costs increase, such a probability decreases further.
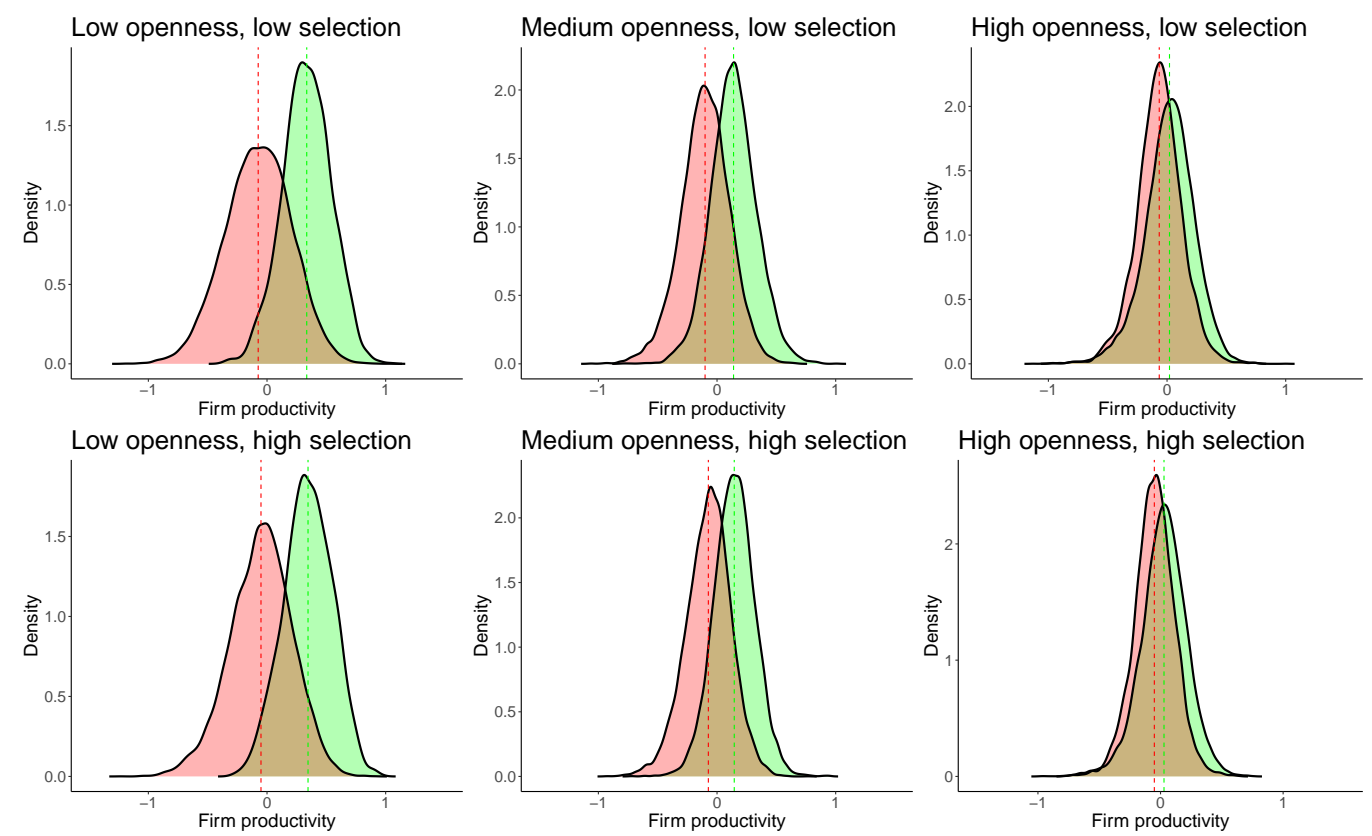

Figure 7: Log-centered productivity distribution conditional upon the export status (exporters in green; non-exporters in red). Dashed lines represent conditional averages. Results are pooled over Monte Carlo simulations.

Similar considerations apply to the relation between export status and firm size. The empirical evidence indicates that on average exporters are larger than non exporters (see SF14 in Table 1). At the same time, there are some large non-exporting firms as well as small exporting firms (cf. SF13). Our model is also able to replicate this feature, which is presented in Figure 8. Furthermore, in line with di Giovanni et al. (2011), lower trade barriers increase the average size difference between exporters and non-exporters. This effect, can be explained by looking at the distributions of exporters' market shares generated by our model (see Figure 9). These distributions deviate from the Log-Normal benchmark in all competition regimes, which indicates that few firms are responsible for a large bulk of the export activity (a result in line with SF15). Notice that the deviation from the Log-Normal benchmark is stronger when trade opennes is higher. As we already noticed above, removing trade barriers unleash competition among firms generating higher levels of market concentration. The result is that few and very productive firms are able to gain large market shares 
both in local as well as in foreign markets.
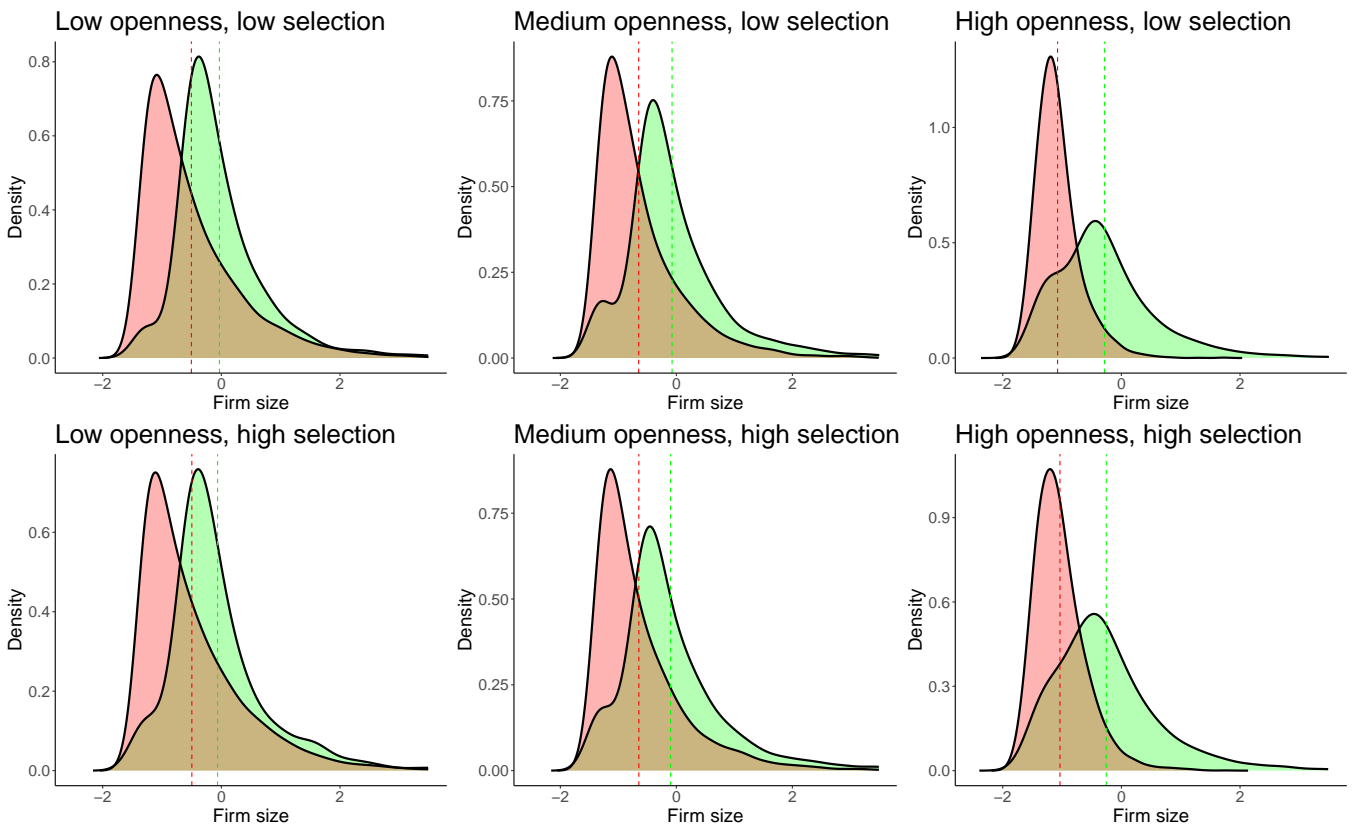

Figure 8: Log-normalized size densities (pooled from the last period of each simulation) of exporters (green) against non-exporters (red). The dashed lines are the averages.
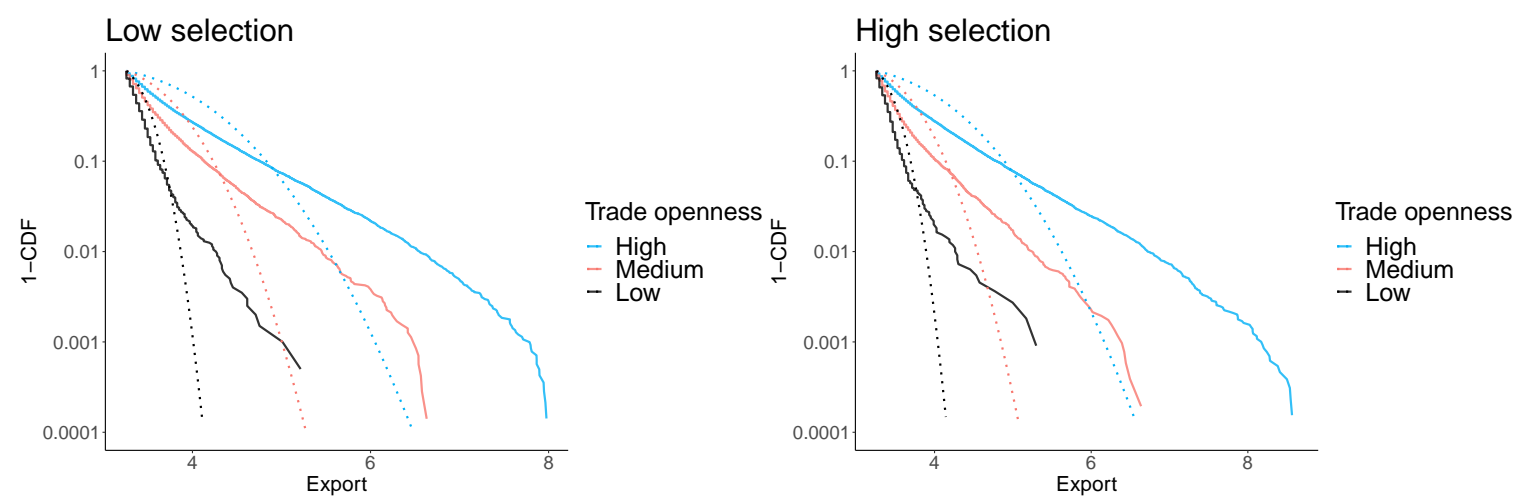

Figure 9: Pooled complementary cumulative distributions of exporters size in the local market (continuous lines) against the log-normal fit (dotted lines). Both the $\mathrm{x}$ and the $\mathrm{y}$-axis are in log terms.

A branch of the empirical trade literature has also investigated the relation between firm export activity and firm growth rate volatility, finding that these two variables are positively related (cf SF17). Table 13 reports the model-generated firm growth volatilities: those conditional upon export status (first two columns) and the unconditional one (last column). In line with the empirical evidence, exporters' growth is more volatile than the non-exporters one. However, the wedge between the two volatilities decreases with trade openness. Clearly, higher trade openness removes the shield from competition represented by iceberg costs. The result is that domestic firms have to compete with more foreign firms, which maps into a more more volatile growth process for every 
firm in the market.

\begin{tabular}{ccccc}
\hline \multicolumn{2}{c}{ Competition Regime } & \multicolumn{3}{c}{ Firm Growth Rate Volatility } \\
\hline $\begin{array}{c}\text { Selection } \\
\text { Intensity }\end{array}$ & $\begin{array}{c}\text { Trade } \\
\text { Openness }\end{array}$ & $\begin{array}{c}\text { Exporters } \\
\text { Volatility }\end{array}$ & $\begin{array}{c}\text { Non-exporters } \\
\text { Volatility }\end{array}$ & $\begin{array}{c}\text { All firms } \\
\text { Volatility }\end{array}$ \\
\hline \multirow{4}{*}{ Low } & \multirow{2}{*}{ Low } & 0.306 & 0.091 & 0.141 \\
& & $(0.008)$ & $(0.007)$ & $(0.02)$ \\
& \multirow{2}{*}{ Medium } & 0.306 & 0.142 & 0.232 \\
& & $(0.005)$ & $(0.007)$ & $(0.02)$ \\
& \multirow{2}{*}{ High } & 0.31 & 0.227 & 0.309 \\
& $(0.008)$ & $(0.02)$ & $(0.019)$ \\
\hline \multirow{4}{*}{ High } & \multirow{2}{*}{ Low } & 0.339 & 0.099 & 0.144 \\
& \multirow{2}{*}{ Medium } & $(0.011)$ & $(0.003)$ & $(0.022)$ \\
& & 0.333 & 0.148 & 0.243 \\
& \multirow{2}{*}{ High } & $0.011)$ & $(0.01)$ & $(0.019)$ \\
& & $(0.005)$ & $(0.023)$ & $(0.009)$ \\
\hline \hline
\end{tabular}

Table 13: Monte Carlo averages of the firm growth volatility of the of exporters, non-exporters and all firms.

Finally, a large literature has analyzed of the role that innovative activity plays in determining export performance. The main empirical conclusion is that innovation positively affects firms' participation in foreign markets as well as their performances (see SF18). In our model, the effects of innovation activity are captured by the learning process, which brings permanent shocks to the productivity level of a firm. Table 14 reports the correlation emerging in our model between innovation activity on the one hand and export participation and export volume on the other hand. ${ }^{25}$ The table indicates that innovation activities are positively correlated with both firm export participation and export volumes. Moreover, correlations increase in regimes with higher trade openness. As we already observed, the decrease of trade barriers removes the impediments to entry and growth in foreign markets. This implies that - for the same level of learning activity - a large share of firms is able to enter in foreign markets. These entrant firms are also able to reap a higher number of market opportunities from incumbent firms. This suggests that the link between innovation activities and export participation and volumes become stronger in more open markets.

\footnotetext{
${ }^{25}$ In our model innovation activity is not endogenously modelled but is implicit into the stochastic process of learning. Here we use as a proxy of innovation activity, the number of times an individual firm improves its productivity by obtaining a positive shock in equation (10).
} 


\begin{tabular}{lccc}
\hline \multicolumn{2}{c}{ Competition Regime } & \multicolumn{2}{c}{ Correlation with Innovation Activity } \\
\hline \multirow{2}{*}{ Selection } & Openness & Export volume & Export participation \\
& \multirow{4}{*}{ Low } & 0.328 & 0.659 \\
& & $(0.039)$ & $(0.036)$ \\
\multirow{2}{*}{ Low } & Medium & 0.476 & 0.833 \\
& & $(0.06)$ & $(0.021)$ \\
& High & 0.542 & 0.913 \\
& & $(0.067)$ & $(0.005)$ \\
& \multirow{4}{*}{ Low } & 0.252 & 0.59 \\
& & $(0.041)$ & $(0.042)$ \\
High & Medium & 0.431 & 0.793 \\
& & $(0.061)$ & $(0.022)$ \\
& High & 0.54 & 0.904 \\
& & $(0.051)$ & $(0.005)$ \\
\hline
\end{tabular}

Table 14: Correlation between innovation activity (frequency of firm learning events), export volume (average export shares) and firm export participation (its average frequency of positive export events).

\section{Conclusions}

We have developed a simple dynamic model of intra-industry international trade. In the model, firm learning, that takes place cumulatively (Dosi et al., 1995, 2017), governs firm competitiveness. Market selection, based on the finite pairwise Pólya urn process, drives the allocation of market opportunities across firms, rewarding bigger and more productive firms. These two general economic forces are also mediated by (i) the intensity of market selection, (ii) the presence of barriers to trade.

Overall, the paper contributes to the literature in three dimensions. First, the introduction for the finite pairwise Pólya urn process, to be interpreted as a reduced form representation of market selection, can be helpful for the development of new and richer models of firm dynamics. We proved that, with a static distribution of firm productivity levels, the market structure converges to a monopoly (either a national or an international one) held by the most productive firm. Second, the full-fledged model featuring firm learning and entry and exit is able to jointly replicate a wide ensemble of stylised facts of international trade and concerning the dynamics at the firm and at the industry level. We thus contribute to the literature in industry and trade dynamics by providing a possible data generating process for these facts based on the interaction between simple mechanisms of cumulative learning and market selection with dynamic increasing returns. Third, we documented how higher degrees of market concentration and volatility are observed in presence of 
a higher market selection and trade openness.

The model could be extended to account for the effect of country asymmetries in both size and learning opportunities. A vast strand of empirical literature has shown that countries differ both in terms of industry size, demand levels and on the ability to generate new technological opportunities and to absorb foreign and advanced technological knowledge. These aspects might impact both on the selection and the learning mechanisms. A second extension could involve a generalization of the model to more than two countries and two sectors. This would allow one sto take into account the heterogeneous spillovers between different pairs of country-sector combinations and the role of multi-product firms. Such a model, could also be calibrated by using the data from Input-Output tables and would allow to better understand the importance of inter-sectoral knowledge flows.

\section{Acknowledgments}

We thank Giovanni Dosi, Flora Bellone, Marco Grazzi, Lionel Nesta, Angelo Secchi, along with several participants at the 2019 European Meeting on Applied Evolutionary Economics (EMAEE 2019), the 2019 Workshop on Economic Science with Heterogeneous Interacting Agents (WEHIA 2019) and the 2020 European Association for Evolutionary Political Economy (EAEPE 2020) where earlier versions of this paper were presented. Mattia Guerini has received funding from the European Union's Horizon 2020 research and innovation program under the Marie Sklodowska-Curie grant agreement No 799412 (ACEPOL). The usual disclaimers apply. 


\section{References}

Acemoglu, D., V. M. Carvalho, A. Ozdaglar, and A. Tahbaz-Salehi (2012, September). The Network Origins of Aggregate Fluctuations. Econometrica 80(5), 1977-2016.

Aghion, P., A. Bergeaud, T. Gigout, M. Lequien, and M. Melitz (2019). Spreading knowledge across the world: Innovation spillover through trade expansion.

Albornoz, F., H. F. Calvo Pardo, G. Corcos, and E. Ornelas (2012). Sequential exporting. fournal of International Economics 88(1), 17-31.

Amador, J. and L. Opromolla (2013, March). Product and destination mix in export markets. Review of World Economics (Weltwirtschaftliches Archiv) 149(1), 23-53.

Armenter, R. and M. Koren (2014, July). A Balls-and-Bins Model of Trade. American Economic Review 104(7), $2127-2151$.

Arthur, W., E. Y.M., and K. Y.M. (1987, June). Path-dependent processes and the emergence of macro-structure. European fournal of Operational Research 30(3), 294-303.

Arthur, W. B. (1989). Competing technologies, increasing returns, and lock-in by historical events. Economic Journal 99(394), 116-31.

Assenza, T., D. DelliGatti, J. Grazzini, and G. Ricchiuti (2016). "heterogeneous firms and international trade: the role of productivity and financial fragility". CESifo Working Paper Series 5959, CESifo Group Munich.

Atkeson, A. and A. T. Burstein (2010, June). Innovation, Firm Dynamics, and International Trade. fournal of Political Economy 118(3), 433-484.

Axtell, R. L. (2001). "zipf distribution of u.s. firm sizes". Science, 293.

Baily, M. N., C. Hulten, and D. Campbell (1992). Productivity dynamics in manufacturing plants. Brookings Papers on Economic Activity 23(1992 Microeconomics), 187-267.

Balassa, B. (1966). "tariff reductions and trade in manufactures among the industrial countries". New Haven, Conn.: Yale University, Economic Growth Center.

Baldwin, R. (2005). Heterogeneous Firms and Trade: Testable and Untestable Properties of the Melitz Model. NBER Working Paper No. 11471.

Barba Navaretti, G., D. Castellani, and F. Pieri (2014, Dec). Age and firm growth: evidence from three european countries. Small Business Economics 43(4), 823-837.

Bartelsman, E. and P. Dhrymes (1998, January). Productivity Dynamics: U.S. Manufacturing Plants, 1972-1986. Journal of Productivity Analysis 9(1), 5-34.

Bartelsman, E., S. Scarpetta, and F. Schivardi (2003, January). Comparative analysis of firm demographics and survival: Micro-level evidence for the oecd countries. OECD Economics Department Working Papers 348, OECD Publishing.

Bernard, A. and J. Jensen (2004). Why some firms export. The Review of Economics and Statistics 86(2), 561-569.

Bernard, A. and J. Wagner (2001). Export entry and exit by german firms. Review of World Economics (Weltwirtschaftliches Archiv) 137(1), 105-123.

Bernard, A. B. and J. Bradford Jensen (1999, February). Exceptional exporter performance: cause, effect, or both? Journal of International Economics 47(1), 1-25. 
Bernard, A. B., J. Eaton, J. B. Jensen, and S. Kortum (2003). Plants and Productivity in International Trade. American Economic Review 93(4), 1268-1290.

Bernard, A. B. and J. B. Jensen (1995). Exporters, Jobs, and Wages in U.S. Manufacturing: 1976-1987. Brookings Papers on Economic Activity 26(1995 Micr), 67-119.

Bernard, A. B., J. B. Jensen, S. J. Redding, and P. K. Schott (2007, Summer). Firms in International Trade. Journal of Economic Perspectives 21(3), 105-130.

Bernard, A. B., J. B. Jensen, S. J. Redding, and P. K. Schott (2009, May). The Margins of US Trade. American Economic Review 99(2), 487-493.

Bernard, A. B., J. B. Jensen, S. J. Redding, and P. K. Schott (2012, July). The Empirics of Firm Heterogeneity and International Trade. Annual Review of Economics 4(1), 283-313.

Bernard, A. B., J. B. Jensen, S. J. Redding, and P. K. Schott (2018, June). Global Firms. Fournal of Economic Literature 56(2), 565-619.

Bernard, A. B., S. J. Redding, and P. K. Schott (2011). Multiproduct Firms and Trade Liberalization. The Quarterly fournal of Economics 126(3), 1271-1318.

Bils, M. (1989). Pricing in a customer market. The Quarterly fournal of Economics 104(4), 699-718.

Blume, L. and D. Easley (1992). Evolution and market behavior. fournal of Economic Theory 58(1), 9 - 40.

Bottazzi, G., G. Dosi, G. Fagiolo, and A. Secchi (2007, September). Modeling industrial evolution in geographical space. Journal of Economic Geography 7(5), 651-672.

Bottazzi, G., G. Dosi, N. Jacoby, A. Secchi, and F. Tamagni (2010). Corporate performances and market selection: some comparative evidence. Industrial and Corporate Change 19(6), 1953-1996.

Bottazzi, G. and D. Giachini (2019). Far from the madding crowd: Collective wisdom in prediction markets. Quantitative Finance 19(9), 1461-1471.

Bottazzi, G., D. Pirino, and F. Tamagni (2015, July). Zipf law and the firm size distribution: a critical discussion of popular estimators. Fournal of Evolutionary Economics 25(3), 585-610.

Bottazzi, G. and A. Secchi (2003, December). Common Properties and Sectoral Specificities in the Dynamics of U.S. Manufacturing Companies. Review of Industrial Organization 23, 217-232.

Bottazzi, G. and A. Secchi (2006a). Explaining the distribution of firm growth rates. The RAND fournal of Economics 37(2), 235-256.

Bottazzi, G. and A. Secchi (2006b, October). Gibrat's Law and diversification. Industrial and Corporate Change 15(5), 847-875.

Bottazzi, G., A. Secchi, and F. Tamagni (2008, August). Productivity, profitability and financial performance. Industrial and Corporate Change 17(4), 711-751.

Burstein, A. and M. J. Melitz (2011, April). Trade Liberalization and Firm Dynamics. (16960).

Calvino, F., C. Criscuolo, C. Menon, and A. Secchi (2018). Growth volatility and size: A firm-level study. Journal of Economic Dynamics and Control 90(C), 390-407.

Calvino, F., D. Giachini, and M. Guerini (2020). The age distribution of business firms. LEM Working Papers Series (20). 
Campa, J. (2004). Exchange rates and trade: How important is hysteresis in trade? European Economic Review 48(3), 527-548.

Castaldi, C. and G. Dosi (2009). The patterns of output growth of firms and countries: Scale invariances and scale specificities. Empirical Economics 37(3), 475-495.

Castaldi, C. and S. Sapio (2008, August). Growing like mushrooms? Sectoral evidence from four large European economies. Fournal of Evolutionary Economics 18(3), 509-527.

Ćede, U., B. Chiriacescu, P. Harasztosi, T. Lalinsky, and J. Meriküll (2018, May). Export characteristics and output volatility: comparative firm-level evidence for CEE countries. Review of World Economics (Weltwirtschaftliches Archiv) 154(2), 347-376.

Clauset, A., C. R. Shalizi, and M. Newman (2009, August). Power Law Distributions in Empirical Data. SIAM Review 51(4), 661-703.

Coad, A. (2010a). Investigating the exponential age distribution of firms. Economics - The Open-Access, OpenAssessment E-fournal 4, 1-30.

Coad, A. (2010b, September). The Exponential Age Distribution and the Pareto Firm Size Distribution. Fournal of Industry, Competition and Trade 10(3), 389-395.

Coad, A. (2018). Firm age: a survey. Fournal of Evolutionary Economics 28(1), 13-43.

di Giovanni, J. and A. A. Levchenko (2009, August). Trade Openness and Volatility. The Review of Economics and Statistics 91(3), 558-585.

di Giovanni, J. and A. A. Levchenko (2012). Country Size, International Trade, and Aggregate Fluctuations in Granular Economies. Journal of Political Economy 120(6), 1083-1132.

di Giovanni, J., A. A. Levchenko, and I. Mejean (2014, July). Firms, Destinations, and Aggregate Fluctuations. Econometrica 82(4), 1303-1340.

di Giovanni, J., A. A. Levchenko, and I. Mejean (2019). Foreign Shocks as Granular Fluctuations.

di Giovanni, J., A. A. Levchenko, and R. Rancière (2011, September). Power laws in firm size and openness to trade: Measurement and implications. Fournal of International Economics 85(1), 42-52.

Doms, M. and E. J. Bartelsman (2000, September). Understanding Productivity: Lessons from Longitudinal Microdata. Journal of Economic Literature 38(3), 569-594.

Dosi, G. (1988). Sources, procedures, and microeconomic effects of innovation. Fournal of economic literature, $1120-1171$.

Dosi, G. (2007). Statistical regularities in the evolution of industries: a guide through some evidence and challenges for the theory. In F. Malerba and S. Brusoni (Eds.), Perspectives on Innovation. Cambridge University Press.

Dosi, G., Y. Ermoliev, and Y. Kaniovski (1994, January). Generalized urn schemes and technological dynamics. Journal of Mathematical Economics 23(1), 1-19.

Dosi, G., G. Fagiolo, M. Napoletano, and A. Roventini (2013). Income distribution, credit and fiscal policies in an agent-based keynesian model. Journal of Economic Dynamics and Control 37(8), 1598-1625.

Dosi, G., G. Fagiolo, M. Napoletano, A. Roventini, and T. Treibich (2015). Fiscal and monetary policies in complex evolving economies. Fournal of Economic Dynamics and Control 52, 166-189. 
Dosi, G., G. Fagiolo, and A. Roventini (2010, September). Schumpeter meeting Keynes: A policy-friendly model of endogenous growth and business cycles. Journal of Economic Dynamics and Control 34(9), 1748-1767.

Dosi, G. and M. Grazzi (2006). Industrial and Corporate Change 15(1), 173-202.

Dosi, G., M. Grazzi, and D. Moschella (2015). Technology and costs in international competitiveness: From countries and sectors to firms. Research Policy 44(10), 1795 - 1814.

Dosi, G. and Y. Kaniovski (1994). On "badly behaved" dynamics. Fournal of Evolutionary Economics 4(2), 93-123.

Dosi, G., O. Marsili, L. Orsenigo, and R. Salvatore (1995, Dec). Learning, market selection and the evolution of industrial structures. Small Business Economics 7(6), 411-436.

Dosi, G., A. Moneta, and E. Stepanova (2019, April). Dynamic increasing returns and innovation diffusion: bringing Polya Urn processes to the empirical data. Industry and Innovation 26(4), 461-478.

Dosi, G., D. Moschella, E. Pugliese, and F. Tamagni (2015). Productivity, market selection, and corporate growth: comparative evidence across us and europe. Small Business Economics 45(3), 643-672.

Dosi, G. and R. R. Nelson (2010). Chapter 3 - technical change and industrial dynamics as evolutionary processes. In B. H. Hall and N. Rosenberg (Eds.), Handbook of The Economics of Innovation, Vol. 1, Volume 1 of Handbook of the Economics of Innovation, pp. 51 - 127. North-Holland.

Dosi, G., M. C. Pereira, and M. E. Virgillito (2017). The footprint of evolutionary processes of learning and selection upon the statistical properties of industrial dynamics. Industrial and Corporate Change 26(2), $187-210$.

Dunne, T., M. Roberts, and L. Samuelson (1988). Patterns of firm entry and exit in u.s. manufacturing industries. RAND fournal of Economics 19(4), 495-515.

Easterly, W., R. Islam, and J. Stiglitz (2001). Shaken and stirred: explaining growth volatility. Annual World Bank Conference on Development Economics, World Bank, 191-211.

Eaton, J., M. Eslava, K. M., and T. M. (2008). "export dynamics in colombia: firm-level evidence". in "The organization of firms in a global economy", ed. E Helpman, D Marin, T Verdier, 8:231-72. Cambridge MA: Harvard University Press.

Eaton, J., S. Kortum, and F. Kramarz (2011, September). An Anatomy of International Trade: Evidence From French Firms. Econometrica 79(5), 1453-1498.

Fagiolo, G., M. Napoletano, and A. Roventini (2008). Are output growth-rate distributions fat-tailed? some evidence from OECD countries. fournal of Applied Econometrics 23(5), 639-669.

Fontagné, L. and M. Freudenberg (1997, January). Intra-Industry Trade: Methodological Issues Reconsidered. (1997-01).

Foster, L., J. Haltiwanger, and C. Krizan (2001). Aggregate productivity growth: Lessons from microeconomic evidence. In New Developments in Productivity Analysis, pp. 303-372. National Bureau of Economic Research, Inc.

Freund, C. and M. D. Pierola (2015, December). Export Superstars. The Review of Economics and Statistics 97(5), 1023-1032.

Fu, D., F. Pammolli, S. V. Buldyrev, M. Riccaboni, K. Matia, K. Yamasaki, and H. E. Stanley (2005). The growth of business firms: Theoretical framework and empirical evidence. Proceedings of the National Academy of Sciences 102(52), 18801-18806. 
Gabaix, X. (2011, May). The Granular Origins of Aggregate Fluctuations. Econometrica 79(3), 733-772.

Gaubert, C. and O. Itskhoki (2018, July). Granular comparative advantage. Working Paper 24807, National Bureau of Economic Research.

Geroski, P. (1995). What do we know about entry? International fournal of Industrial Organization 13(4), 421-440

Gibrat, R. (1931). Les inégalités économiques: applications aux inégalités des richesses, à la concentration des entreprises... d'une loi nouvelle, la loi de l'effet proportionnel. Libr. du Recueil Sirey.

Grazzi, M., N. Mathew, and D. Moschella (2021, 03). Making one's own way: jumping ahead in the capability space and exporting among Indian firms. Fournal of Evolutionary Economics.

Greenwald, B. and J. Stiglitz (2005). Macroeconomic fluctuations in an economy of phelps-winter markets. In P. Aghion, F. Roman, J. Stiglitz, and M. Woodford (Eds.), Knowledge, Information, and Expectations in Modern Macroeconomics: In Honor of Edmund S. Phelps. Princeton University Press.

Grubel, H. G. and P. J. Lloyd (1975). " intra-industry trade: the theory and measurement of international trade in differentiated products". New York: Wiley.

Guerini, M., P. Musso, and L. Nesta (2021). Can you jump this high? quantifying barriers to market participation. Economic Modelling 98, 192-217.

Hopenhayn, H. A. (1992, September). Entry, Exit, and Firm Dynamics in Long Run Equilibrium. Econometrica $60(5), 1127-1150$.

Hymer, S. and P. Pashigian (1962). Firm size and rate of growth. fournal of Political Economy 70.

Ijiri, Y. and H. A. Simon (1975). Some Distributions Associated with the Bose-Einstein Statistics. Proceeding of the National Academy of Science 72.

Ijiri, Y. and H. A. Simon (1977). Skew Distributions and the Sizes of Business Firms. Amsterdam: NorthHolland.

Impullitti, G., A. A. Irarrazabal, and L. D. Opromolla (2013). A theory of entry into and exit from export markets. Fournal of International Economics 90(1), 75-90.

Jovanovic, B. (1982). Selection and the evolution of industry. Econometrica 50(3), 649-70.

Krugman, P. R. (1979, November). Increasing returns, monopolistic competition, and international trade. fournal of International Economics 9(4), 469-479.

Luttmer, E. G. J. (2007). Selection, Growth, and the Size Distribution of Firms. The Quarterly fournal of Economics 122(3), 1103-1144.

Malerba, F. and R. Nelson (2011, December). Learning and catching up in different sectoral systems: evidence from six industries. Industrial and Corporate Change 20(6), 1645-1675.

Mayer, T., M. J. Melitz, and G. I. P. Ottaviano (2014, February). Market Size, Competition, and the Product Mix of Exporters. American Economic Review 104(2), 495-536.

Mayer, T. and G. Ottaviano (2008). The happy few: The internationalisation of european firms. Intereconomics: Review of European Economic Policy 43(3), 135-148.

Melitz, M. J. (2003). The impact of trade on intra-industry reallocations and aggregate industry productivity. Econometrica. 
Melitz, M. J. and D. Trefler (2012, Spring). Gains from Trade When Firms Matter. Fournal of Economic Perspectives 26(2), 91-118.

Nelson, R. and S. Winter (1982). "an evolutionary theory of economic change". Harvard University Press.

Olley, G. S. and A. Pakes (1996, November). The Dynamics of Productivity in the Telecommunications Equipment Industry. Econometrica 64(6), 1263-1297.

Pavcnik, N. (2002, 01). Trade Liberalization, Exit, and Productivity Improvements: Evidence from Chilean Plants. The Review of Economic Studies 69(1), 245-276.

Phelps, E. and S. Winter (1970). Optimal price policy under atomistic competition. In E. Phelps (Ed.), The Microeconomic Foundations of Employment and Inflation Theory. Norton \& Company.

Riccaboni, M., F. Pammolli, S. V. Buldyrev, L. Ponta, and H. E. Stanley (2008). The size variance relationship of business firm growth rates. 105(50), 19595-19600.

Rodrik, D. (1998). Why do more open economies have bigger governments? Journal of Political Economy 106(5), 997-1032.

Rotemberg, J. J. and M. Woodford (1991). Markups and the business cycle. NBER macroeconomics annual 6, 63-129.

Santarelli, E., L. Klomp, and R. Thurik (2006, 06). Gibrat's law : An overview of the empirical literature. Entrepreneurship, Growth and Innovation: The Dynamics of Firms and Industries, 41-73.

Schreiber, J. (2001). "urn models, replicator processes, and random genetic drift". SIAM f. Appl. Math., 61(6).

Simon, H. A. (1955). On a class of skewed distribution functions. Biometrika 42.

Simon, H. A. and C. P. Bonini (1958). The size distribution of business firms. The American Economic Review 48(4), 607-617.

Stanley, M., S. Buldyrev, S. Havlin, R. N. Mantegna, M. A. Salinger, and S. Eugene. (1996). "scaling behaviour in the growth of companies". Nature, 379.

Sutton, J. (2002). The variance of firm growth rates: the 'scaling' puzzle. Physica A: Statistical Mechanics and its Applications 312(3), 577 - 590.

Syverson, C. (2011, June). What Determines Productivity? Journal of Economic Literature 49(2), 326-365.

Trefler, D. (2004). The long and short of the canada-u.s. free trade agreement. The American Economic Review 94(4), 870-895.

Vannoorenberghe, G. (2012). Firm-level volatility and exports. Journal of International Economics 86(1), 57-67. 


\section{A Proofs of the propositions}

In this appendix we report the proofs of the propositions stated in the paper

Proof of proposition 1. Consider the expected size shock $\xi_{i, k, t}$ of firm $i$ at iteration $k$ and time $t$ when the market is not in monopoly:

$$
\mathbb{E}\left(\xi_{i, k, t}\right)=\sum_{\forall i \neq j} z_{i j, k, t} p_{i j, k, t}
$$

Given a continuous distribution of productivity levels $a_{i t}$ of the incumbent firms - defined as the firms with strictly positive size - there always exists a most productive incumbent $\bar{i}$ characterized by $a_{\bar{i} t}=\max \left\{a_{i t}\right\}$ and a least productive incumbent $\underline{i}$ characterized by $a_{\underline{i}}=\min \left\{a_{i t}\right\}$. Thus, the following statements holds true:

1. $\mathbb{E}\left(\xi_{\bar{i}, k, t}\right)>0, \min \left(\xi_{\bar{i}, k, t}\right)=0$

2. $\mathbb{E}\left(\xi_{i, k, t}\right)<0, \max \left(\xi_{i, k, t}\right)=0$

The first statement tells us that the most productive firm has always positive expected size shock and can only be hit by non-negative shocks. As a consequence, its size cannot reach 0 and the only fixed point of firm $\bar{i}$ is $M$ (see Equation (7)). Also notice that the law of motion of size of all the firms different from $\bar{i}$ cannot reach the fixed point $M$ by the same fact that firm $\bar{i}$ market opportunities cannot be stolen by any of the other incumbents. According to the second statement, the least productive firm always experiences negative expected size shock and non-positive shocks. Since $\sum_{i} \mathbb{E}\left(\xi_{i, k, t}\right)=0$, due to the symmetry between positive and negative size shocks to firms, the system converges to monopoly by iterating the process for a sufficiently large value of $K$ because firms are drawn to compete with positive probabilities.

Proof of proposition 2. The productivity of an exporting firm may suffer from the presence of iceberg cost $c$ as described by Equation (9). In the case 1 of the proposition, iceberg costs are null. Accordingly, the economies of the two countries are symmetric as if they were composed by the same $2 \cdot N$ domestic and foreign firms. In this case, Proposition 1 tells us that the market will converge to an international monopoly wherein shares are held by the same most productive firm.

For the proof of cases 2 and 3, we introduce the following notation. Let us denote the maximum of firm productivity in country $h=1,2$ as $M_{h}$ and the $i$ th firm productivity as $a_{i, h, t}$. We define the probability of international monopoly as the sum of the probability of two events:

$$
\mathrm{P}(\text { International Monopoly })=P\left(M_{2}<(1-c) M_{1}\right)+P\left(M_{1}<(1-c) M_{2}\right)
$$


where $P\left(M_{2}<(1-c) M_{1}\right)$ is the probability that the most productive firm belongs to country 1 and, similarly, $P\left(M_{1}<(1-c) M_{2}\right)$ is the probability that it belongs to country 2 , irrespectively of trade costs $c$. Given that Equation (12) describes the probability that the same firm is the most productive in both the markets, it is also the probability that the model converges to international monopoly (see proposition 1).

Let us now consider the case $2(c \in(0,1))$. We decompose the first component of Equation (12):

$$
\begin{gathered}
P\left(M_{2}<(1-c) \cdot M_{1}\right)= \\
=P\left(a_{1,2, t}<(1-c) \cdot M_{1}, a_{2,2, t}<(1-c) \cdot M_{1}, \ldots, a_{N, 2, t}<(1-c) \cdot M_{1}\right)= \\
=P\left(a_{1,2, t}<(1-c) \cdot M_{1}\right) \cdot P\left(a_{2,2, t}<(1-c) \cdot M_{1}\right) \cdot \ldots \cdot P\left(a_{N, 2, t}<(1-c) \cdot M_{1}\right)
\end{gathered}
$$

Where each component can be rewritten as follows by taking into account that the draws $a_{i, h, t}$ are $i . i . d$. and so are the differences $\left(D_{h}\right)$ between them:

$$
\begin{gathered}
P\left(a_{1,2, t}<(1-c) M_{1}\right)= \\
P\left(a_{1,2, t}<(1-c) \cdot a_{1,1, t}, a_{1,2, t}<(1-c) \cdot a_{2,1, t}, \ldots, a_{1,2, t}<(1-c) \cdot a_{N, 1, t}\right)= \\
P\left(a_{1,2, t}-(1-c) \cdot a_{1,1, t}<0\right) \cdot P\left(a_{1,2, t}-(1-c) \cdot a_{2,1, t}<0\right) \cdot, \ldots, P\left(a_{1,2, t}-(1-c) \cdot a_{N, 1, t}<0\right)= \\
P\left(D_{1}<0\right) \cdot P\left(D_{1}<0\right) \cdot, \ldots, P\left(D_{1}<0\right)=P\left(D_{1}<0\right)^{N}
\end{gathered}
$$

By plugging Equation (14) into Equation (13) we find:

$$
P\left(M_{2}<(1-c) M_{1}\right)=P\left(D_{1}<0\right)^{N^{2}}
$$

Similarly, one can rewrite also the second term of Equation (12) as the product $P\left(D_{2}<0\right)^{N^{2}}$. Accordingly, we get the following final expression for the probability of convergence to an international monopoly:

$$
\mathrm{P}(\text { International Monopoly })=P\left(D_{1}<0\right)^{N^{2}}+P\left(D_{2}<0\right)^{N^{2}}
$$

By looking at Equation (16) we can see that the probability of international monopoly depends on two factors, namely the number of firms $N$ and the difference between the productivity distributions considered. First, as $N$ grows bigger, the probability of international monopoly goes to 0 as it becomes easier to find highly productive firms in each of the two countries considered. Second, the probability that the differences $D_{1}$ and $D_{2}$ are smaller than 0 depends on the iceberg cost $c$. The higher the value of $c$, the lower the probability that the differences in productivity $D_{1}$ and $D_{2}$ are negative. One important remark is needed. We assumed 
symmetry in the firm productivity distributions of the two countries. In this respect, a productivity absolute advantage of a country vis-à-vis the other would yield the same effect of imposing an asymmetric iceberg cost $c$.

Finally, in case $3(c=1)$ Equation (12) becomes:

$$
\mathrm{P}(\text { International Monopoly })=P\left(M_{2}<0\right)+P\left(M_{1}<0\right)=0
$$

Because the firm productivity cannot take negative values, implying $P\left(M_{2}<0\right)=P\left(M_{1}<0\right)=0$. 


\section{ABOUT OFCE}

The Paris-based Observatoire français des conjonctures économiques (OFCE), or French Economic Observatory is an independent and publicly-funded centre whose activities focus on economic research, forecasting and the evaluation of public policy.

Its 1981 founding charter established it as part of the French Fondation nationale des sciences politiques (Sciences Po), and gave it the mission is to "ensure that the fruits of scientific rigour and academic independence serve the public debate about the economy". The OFCE fulfils this mission by conducting theoretical and empirical studies, taking part in international scientific networks, and assuring a regular presence in the media through close cooperation with the French and European public authorities. The work of the OFCE covers most fields of economic analysis, from macroeconomics, growth, social welfare programmes, taxation and employment policy to sustainable development, competition, innovation and regulatory affairs.

\section{ABOUT SCIENCES PO}

Sciences $\mathrm{Po}$ is an institution of higher education and research in the humanities and social sciences. Its work in law, economics, history, political science and sociology is pursued through ten research units and several crosscutting programmes.

Its research community includes over two hundred twenty members and three hundred fifty PhD candidates. Recognized internationally, their work covers a wide range of topics including education, democracies, urban development, globalization and public health.

One of Sciences Po's key objectives is to make a significant contribution to methodological, epistemological and theoretical advances in the humanities and social sciences. Sciences Po's mission is also to share the results of its research with the international research community, students, and more broadly, society as a whole.

\section{SciencesPo}

